\title{
Studies on Characterisation of SBS Polymer Modified and Neat Bituminous Mixes Using Warm Mix Asphalt for Paving Applications
}

\author{
Awanti S. S. ${ }^{1}$, Anilkumar L. ${ }^{2}$ \\ ${ }^{1}$ Department of Civil Engineering, Poojya Doddappa Appa College of Engineering, Kalaburgi, India \\ ${ }^{2}$ Department of Civil Engineering, Govt Engg College, Raichur, India
}

Email address:

Anilkumarcv495@gmail.com (Anilkumar L.)

\section{To cite this article:}

Awanti S. S., Anilkumar L. Studies on Characterisation of SBS Polymer Modified and Neat Bituminous Mixes Using Warm Mix Asphalt for Paving Applications. International Journal of Fluid Mechanics \& Thermal Sciences. Vol. 7, No. 3, 2021, pp. $27-52$.

doi: $10.11648 /$ j.ijfmts.20210703.12

Received: June 3, 2021; Accepted: September 3, 2021; Published: November 23, 2021

\begin{abstract}
With increasing concerns of global warming and increasing exhausation of gases, the asphalt industry looking for alternative for hot mix asphalt (HMA). Warm mix asphalt (WMA) is a fast emerging new technology which has a potential of revolutionalizing the production of asphalt mixtures. WMA technology allows the mixing, lay down and compaction of asphalt mixes at significantly lower temperatures compared to hot mix asphalt (HMA). The technology can reduce production temperatures by as much as 30 percent. Asphalt mixes are generally produced at $150^{\circ} \mathrm{C}$ or greater temperatures depending mainly on type of binder used. WMA mixes can be produced at temperatures of about $120^{\circ} \mathrm{C}$ or lower. In this study an attempt has been made to compare HMA (VG-30 and WMA (SBS-PMB-40) with organic additives (Zycotherm, Sasobit and Evotherm) with various dosages on Marshall properties for Dense Bituminous Macadam (DBM), Grade-2. the adopted mixing temperatures for $\mathrm{HMA}$ was $155^{\circ} \mathrm{C}, 130^{\circ} \mathrm{C}$, and $120^{\circ} \mathrm{C}$ and mixing temperature for WMA was $130^{\circ} \mathrm{C}$ and $120^{\circ} \mathrm{C}$. The laboratory study concludes that stability and Marshall properties for WMA mix were improved by addition of additives.
\end{abstract}

Keywords: Wma, Hma, Sbs-Pmb-40, Vg-30, Sasobit, Evotherm, Asphalt Mixes, Marshall Properties

\section{Introduction}

Warm mix asphalt (WMA) refers to asphalt concrete mixtures that are produced at lower temperatures than the temperatures typically used in the production of hot mix asphalt (HMA). WMA is produced at temperatures 50 to $100^{\circ} \mathrm{F}\left(28\right.$ to $56^{\circ} \mathrm{C}$ ) lower than typical HMA, which are typically produced in either batch or drum plants at a discharge temperature of between $280^{\circ} \mathrm{F}\left(138^{\circ} \mathrm{C}\right)$ and $320^{\circ} \mathrm{F}$ $\left(160^{\circ} \mathrm{C}\right)$. For HMA, it is necessary to use these elevated temperatures to dry the aggregate, coat it with the asphalt binder, and achieve the desired workability. The key to the production of HMA is providing sufficient temperature to reduce the viscosity (i.e. resistance to flow) of the asphalt to adequately coat the aggregate. However, WMA achieves adequate coating by reducing the asphalt viscosity in a number of processesand additives. WMA uses the principles of a wide range of technologies such as: organic, chemical, and foaming processes that allow for production and placement of asphalt mix at lower temperatures than those required by traditional HMA technology. Lower placement temperatures are directly related to improved compaction and in-place densities which are often speculated to increase the life of WMA asphalt pavements or make WMA performances comparable to HMA performances.

WMA technology was first developed in Europe in late 1990s. The United States become interested in WMA around 2004 after realizing WMA's success in Europe. Few state DOTs started using WMA around the timeframe of 2008-10.

Furthermore, there are over 35 commercially available WMA technologies in the United States. It is not known yet which technology works better, especially considering New Mexico's local materials, traffic, and weather conditions. Therefore, for WMA to be successfully thorough and comprehensive study is needed to ensure whether the performances of WMA using SBS-PMB is comparable to, or 
better than the performances of HMA. Also, which WMA technology affects pavement performances in what way needs to be known.

Thisstudy makes an initial attempt to evaluate and investigate commercial forms of styrene bit dine styrenepolymer modified bitumen (PMB) and neat bitumen VG 30 grade with and without WMA chemicals, the mix design for sbs-pmb by using WMA technology, optimum dosage, mixing temperatures, in the laboratory and field.

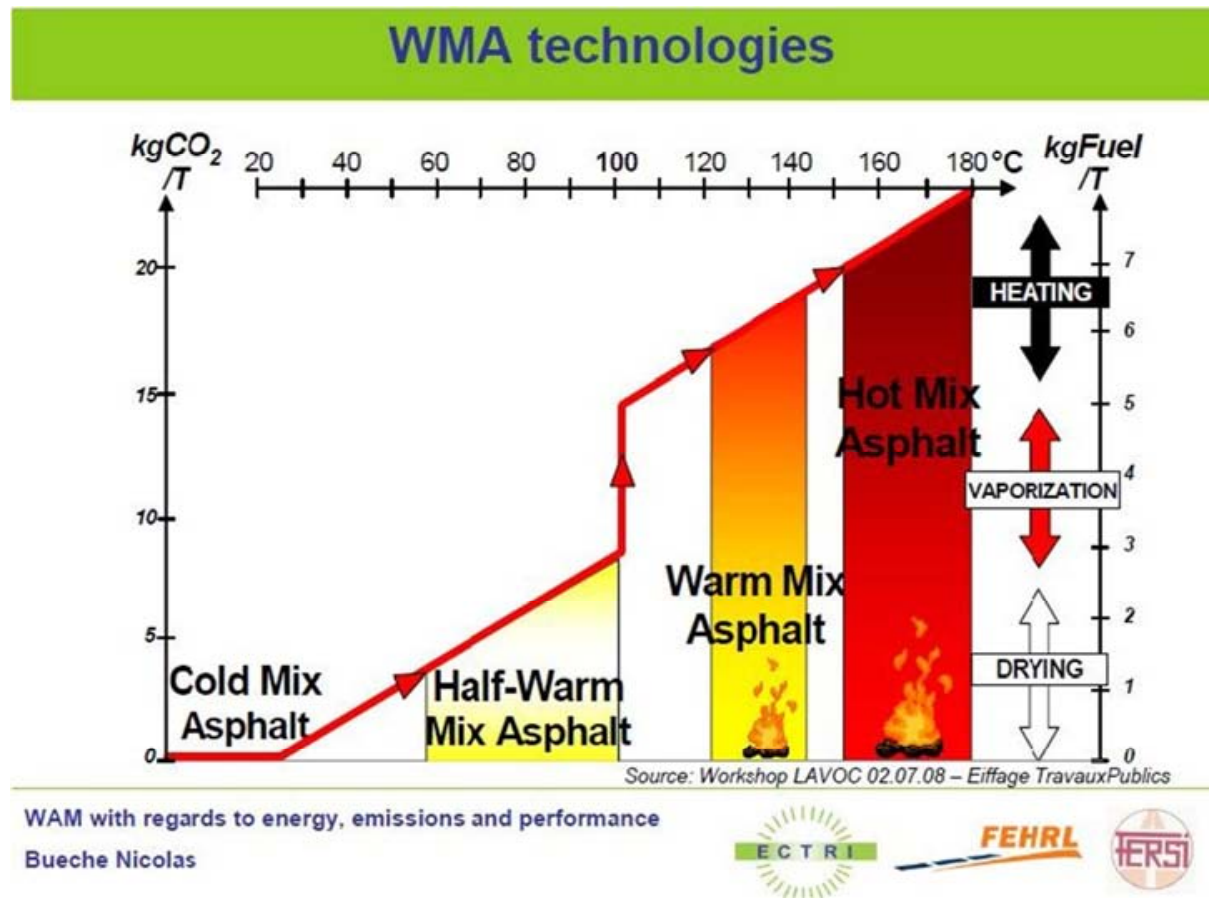

Figure 1. Classification of temperature range.

Objectives of the Present Investigation

Based on the lacunae investigated during literature review the following objectives are drawn:

a. To determine mixing and compaction temperatures for styrene-butadiene- styrene (SBS) polymer modified bitumen 70 grade (SBC-PMB 40) and neat bitumen of VG 30 Grade with and without warm mix asphalt (WMA) chemicals.

b. To determine mixing and compaction temperatures for laboratory short term aged SBS-PMB 40 and VG30 Grade with and without warm mix asphalt chemicals.

c. To evaluate optimum dosage of WMA chemicals for SBS-SBS-PMB-4O and VG30 Grade for virgin as well as aged bitumen.

d. To carryout Marshall Mix design and to determine optimum bitumen content for SBS-SBS-PMB-4O and VG30 Grade bitumen with and without WMA chemicals for virgin as well as aged bitumen.

e. To investigate moisture and temperature susceptibility of SBS-SBS-PMB-4O and VG30 Grade bitumen with and without WMA chemicals for virgin as well as aged bitumen.

Literature Review

Warm Mix Asphalt Technologies

WMA can be produce by one or combination of several technologies involving HMA plant processes and equipment, mineral additives or chemicals that allow the reduction of mix production temperature and fall broadly into one of four categories based on the type of additive used, namely those having water-based additives, water-bearing additives, chemical additives and organic additives. Thirteen WMA technologies are identified by the Warm Mix Asphalt Technical Working Group (WarmMixAsphalt.com). These 13 technologies are listed below with the company name given first and followed by the product/technology name:

Advanced Concepts Engineering Co.: Low Energy Asphalt

Akzo Nobel: Rediset ${ }^{\mathrm{TM}}$ WMX

Arkema Group: CECABASE RT ${ }^{\circledR}$

Astec Industries: Double Barrel Green ${ }^{\circledR}$

Eurovia Services, GmbH: Aspha-Min

Gencor Industries: Ultrafoam GX ${ }^{\mathrm{TM}}$

Maxam Equipment Inc.: Aquablack WMA

McConnaughay Technologies: Low Emission Asphalt

MeadWestvaco Asphalt Innovations: Evotherm ${ }^{\circledR}$

PQ Corporation: Advera

Sasol Wax Americas, Inc.: Sasobit $\mathbb{R}$

Shell Bitumen: WAM Foam

Terex Road building: Warm Mix Asphalt System

WMA Technology Based on Additives

Water-Based Additives

Water-based additives rely upon a foaming action when water is introduced to a warm mix. When small amounts of water are added to a warm mixture, the water vaporizes and is encapsulated in the binder. This produces a foaming action in the binder and temporarily increases the volume of the binder and decreases viscosity, which improves coating and 
workability. Water-based additives must add enough water to cause foaming without adding so much that stripping problems are created.

\section{Foaming Technologies}

Double Barrel Green, Ultrafoam GX, Aquablack WMA and Warm Mix Asphalt System all use some type of a nozzle to inject water into an asphalt binder stream. WAM Foam differs slightly from these technologies as it uses a two component binder system that introduces a soft binder and a hard foamed binder at different times in the mixing cycle. Each technology uses equipment developed by the individual company.

\section{Low Energy Asphalt}

In the Low Energy Asphalt (LEA) process, the coarse aggregate and a portion of the fine aggregate are heated to normal HMA temperatures and mixed with the binder. A coating and adhesion additive ( $0.5 \%$ by weight of binder) is added to the binder in the asphalt supply line to the plant. After the heated portion of the aggregate is coated, cold, wet fine aggregate is added. The wet portion has a moisture content of 3 to $4 \%$. When heated, this moisture is liberated as steam and causes the asphalt coating to foam and encapsulate the uncoated fine aggregate. The final discharge temperature is around $210^{\circ} \mathrm{F}$, which allows the steam to condense into water and aids in the workability and compaction of the mixture.

At present, two types of water-bearing additive WMA technologies are available. Both technologies consist of a synthetic zeolite (sodium aluminum silicate hydrate) that has been hydro-thermally crystallized. The percentage of water held internally by the zeolite is between 18 to $21 \%$ by mass and is released at elevated temperatures. When this is added to the mix at the same time as the binder, water is released as a fine mist, which foams the binder. These materials are purported to not change the performance grade of the binder.

Advera

Advera is a manufactured zeolite that is released at a temperature of $210^{\circ} \mathrm{F}$. Advera is typically added at $0.25 \%$ by total weight of the WMA mix. The technology allows for a $50^{\circ}-70^{\circ} \mathrm{F}$ temperature reduction.

\section{Aspha-Min}

Aspha-Min is a finely powdered synthetic zeolite. The material is released in the temperature range of $185^{\circ}$ to $360^{\circ} \mathrm{F}$. Aspha-Min is typically added at $0.3 \%$ by total weight of the WMA mix. The technology allows for a $54^{\circ} \mathrm{F}$ temperature reduction.

Aspha-min zeolite is hydro-thermally crystallised silicate of natrium-aluminum. It contains approximately $21 \%$ water by weight and is released in the temperature range of 85 $180^{\circ} \mathrm{C}$. Aspha-min is added to an asphalt mixture at a rate of $0.3 \%$ by mass of the mix, which enables approximately a $30^{\circ} \mathrm{C}$ reduction in production and placement temperatures. [2]

Asphaltan B is a low molecular weight esterified wax that enables the application of asphalt blends at lower temperatures by reducing viscosity. It is recommended to use it at the rate of 2 to $4 \%$ of weight relative to the binder. It can be added to the asphalt mixing plant or directly at the binder producer and it can also be added to polymer modified binders. Similar to Sasobit, it acts as an asphalt flow improver by increasing compactability and resistance to rutting. The melting point of Asphaltan B is approximately $99^{\circ} \mathrm{C}$ and it allows reduced production temperatures. [4]

\section{Chemical Additives}

Three chemical additive technologies are described below. Pure chemical additive systems are generally simple from the standpoint that the chemical package may be added to the asphalt binder at the terminal. This results in only minor modifications needed to the asphalt plant or to the mix design process. One technology discussed below (Low Energy Asphalt) is more of a combination of chemical and waterbased foaming technology and does require plant and mix design process modifications.

WMA technologies utilize chemical additives that have little effect on rheological properties of the binder. These products may be supplied in pellet, powder or liquid form, and then mixed into the binder or directly added to the mix. Chemical additives are Surfactants (surface active agents) that reduce surface tension between the polar aggregates and non-polar bitumen, improve wetting and reduces internal friction, and allows a reduction of $28-50^{\circ} \mathrm{C}$ in mixing and compaction temperatures. Typically they are added at the rate of 0.20 to 0.75 percent by weight of bitumen.

\section{Evotherm}

Three technologies are currently produced by Evotherm (Evotherm ET, Evotherm DAT and Evotherm 3G). Evotherm ET contains a chemical package of emulsification agents and anti- stripping agents. During production, the asphalt emulsion along with the chemical package, is used in place of the traditional asphalt binder and is mixed with the aggregate in the traditional HMA plant. Water in the emulsion vaporizes to facilitate mixing. The mixture is purported to provide aggregate coating, workability, adhesion, and improved compaction with no change in job mix formula. The technology allows for a $100^{\circ}-130^{\circ} \mathrm{F}$ reduction in production temperature and no modifications to the plant are required.

Evotherm DAT differs from Evotherm ET in that an emulsion is not used. In this case, the chemical package is injected directly into the asphalt binder line at the plant and results in much less water being added. Evotherm DAT has evidently replaced Evotherm ET.

Evotherm $3 \mathrm{G}$ is a relatively new product marketed as REVIX. At present, detailed information concerning this product is not available. Like the other two Evotherm products, the material can be added at the asphalt terminal or at the plant.

Evotherm is a non-proprietary technology based on a chemical process that includes additives to improve coating and workability, adhesion promoters and emulsion agents. The Evotherm product is delivered in the form of an emulsion with a relatively high asphalt residue (approximately 70\%). Unlike traditional asphalt binders, Evotherm is stored at $80^{\circ} \mathrm{C}\left(176^{\circ} \mathrm{F}\right)$. The water in the emulsion is released from the Evotherm as steam when it is 
mixed with the hot aggregate. The resulting warm mix appears like a hot mix in terms of coating and colour,(Asphalt Institute.) [6].

\section{Low Emission Asphalt}

Low Emission Asphalt is produced by the Low Energy Process described in Section 2.2.2. This process relies on sequential mixing of the asphalt binder containing a chemical additive being added to the hot coarse aggregates, followed by the introduction of wet sand, which creates a foaming action. Production temps as low as $200^{\circ} \mathrm{F}$. Plant modifications in the form of a microwave moisture unit and a shower on the wet sand feed belt, a contact probe to measure mix discharge temperature, and a pump and metering system to administer the chemical additive are required.

\section{Rediset $W M X$}

Rediset is a chemical additive in the pellet form and does not contain water. The material is added at 1.5 to $2.0 \%$ by weight of asphalt binder. Production temperatures are reduced by $60^{\circ} \mathrm{F}$. The material can be added to the binder at the terminal, in the plant supply tank or blown into the mixing drum, which means plant modifications are relatively minor.

Organic Additives

Organic additives are added to the binder to reduce its viscosity. These materials typically have melting points below normal HMA production temperatures. At temperatures above the melting point, these materials reduce the viscosity of the binder making it possible to produce asphalt concrete mixtures at lower temperatures. Below the melting point, they tend to increase the stiffness of the binder.

CECABASE RT

The organic additive used in this technology is unspecified and very few details were available to describe the technology.

\section{Sasobit}

Sasobit is a fine, crystalline, long-chain synthetic wax. The material is added at 3 to $4 \%$ by weight of the total mix. The wax melts at $210^{\circ} \mathrm{F}$ and reduces viscosity of the binder at plant and compaction temperatures. A reduction of production temperatures between $18^{\circ} \mathrm{F}$ and $54^{\circ} \mathrm{F}$ are possible. At service temperatures, Sasobit forms a lattice structure in the asphalt binder that gives the mixture stability. This accounts for the reported resistance to rutting of Sasobitmodified mixes. Sasobit can negatively impact lowtemperature mix properties (Hurley and Prowell, 2005b) (53). Plant modifications in the form of a blending unit for stirring Sasobit into the hot binder prior to mixing with aggregate are required. Sasobit is a product of Sasol Wax International and has been marketed in Europe and Asia since 1997. Sasobit is a mixture of long chain hydrocarbons produced from coal gasification. It does not nitrogen and oxygen. Therefore, it has good oxidation and ageing stability and may bestored indefinitely. Sasobit's melting point is at about $100^{\circ} \mathrm{C}$ andit is completely soluble in bitumen at temperatures above $120^{\circ} \mathrm{C}$, and it does not separate out on storage. It reduces viscosity at working temperatures which makes the asphalt easier to be processed. Anderson et al [5] contain ash- forming materials (metals) or hetero-atoms such as chlorine, sulphur.

Amirkanian, Mallick and Bergendahl, Kirk, button and Chowdary, Hurley and Prowell have demonstrated the laboratory studies as per the NCAT organizations descriptions that the first to conduct laboratory research on WMA technology around 2005/2006 (Hurley and Powell) and produce 3 reports on aspha-min, Sasobit and evatherm. $(141,95,75,26.20,52)$

WMA technology (Apsha-min and Sasobit) can be used to decrease the compaction temperatures of SBS modified asphalt mixtures (WMA mixtures) as compared with HMA mixtures to satisfy the targeted sir voids contents. the fact that those WMA mixtures especially at lower compactions levels, showed lower air voids than HMA mixtures and lower temperature indicates that HMA mixtures at lower temperatures indicates that WMA technologies can help in reducing the compaction.

Based on the binder two aggregates sources and three warm mix asphalt treatments (control, asphanmin and Sasobit), tejas Gandhi (39) and sirjiamirkanian et al, 2008 concluded that asphamin does not significantly lowers the viscosity of the binders at $135^{\circ} \mathrm{C}$ and $120^{\circ} \mathrm{C}$. Soasobit significantly lowers the viscosity of the binders is attributed to the dissolution of wax in the binder. After RTFO aging it was observed that the reducing the aging index percentage of the binders. Also it was observed that the binder containing asphamin had significantly have higher viscosity compared to unmodified binders, and binders containing Sasobit had significantly lower viscosities compared to unmodified binders after RTFO aging at different temperatures. The additives come in different forms, such as liquid, powder, pellet and are administered in the mix production process at different stage. Accordingly, some modification in the bituminous mixing plants is necessary to administer the controlled dosage of the additives. Some additives in liquid form can be pre-blended with bitumen and would need no modification in the conventional mixing plant provided the blended bitumen contains the right dose of additive. Other additives, which are administered in the mix at certain stage during the mix production process, would require some modification in the conventional mixing plants. These modifications would generally require a separate material (additive) feed system and a material metering system (to ensure the right dosage) which should be integrated with computerized plant control system of the mixing plant. The water-based WMA technologies would additionally need a water injection system as well. Apart from such plant modification as required to administer the additives (described above), some modification need would arise out of the need to operate the plant at reduced temperature compared to that for the conventional hot mix production, for example recalibrating the fuel burner, aggregate drying system, bitumen heating system as also to take care of the possible consequences of lower temperature operation, such as contamination of the mix by un-burnt fuel and trapped moisture, condensation of bag house fines, etc. 


\section{Hybrid Technologies}

Hybrid technologies utilize a combination of two or more WMA technologies to achieve the reduction in temperature. For example, Low Energy Asphalt (LEA) utilizes a chemical additive with a water injection system to improve coating at lower temperatures.

Other Technologies

Finally, there are products that were originally developed for other uses, but do incorporate the WMA technology for reducing temperature and hence better utilization of the product. Examples are (sulfur and WMA) and TLAX
(Trinidad lake asphalt and WMA technology) omparision of different WMA additives

In this section, these technologies are described with particular emphasis on the additives and processes used to manufacture the mix. Table provides a summary of information presented in the following sections. From this table, it is seen that the majority of technologies fall within the "water-based additive" category. Mix design process modifications are only required for foaming technologies.

Currently many technologies actively are marketed and available in the world.

Table 1. Illustrates performance of some additives for generating WMA.

\begin{tabular}{|c|c|c|c|c|c|c|}
\hline Additives & Developed by & Types of process & $\begin{array}{l}\text { Recommendation rates of } \\
\text { additives }\end{array}$ & Potential savings & $\begin{array}{l}\text { Country where } \\
\text { technology is used }\end{array}$ & $\begin{array}{l}\begin{array}{l}\text { Reduction in } \\
\text { temperature }\end{array}{ }^{\circ} \mathrm{C} \\
\end{array}$ \\
\hline Sasobit & $\begin{array}{l}\text { Sasol } \\
\text { international } \\
\text { (sasol wax) }\end{array}$ & Organic additives & $\begin{array}{l}0.8-3 \% \text { by weight of organic } \\
\text { binder }\end{array}$ & $\begin{array}{l}\text { Energy } 30 \% \\
\text { Environment: } 20 \%\end{array}$ & $\begin{array}{l}\text { Germany as well as } \\
20 \text { other countries }\end{array}$ & $20-30$ \\
\hline Ashva min & Eurovia & Foaming (W-C) & $0.3 \%$ by totalweight of the mix & $\begin{array}{l}\mathrm{CO}_{2}, \mathrm{SO}_{2}, \mathrm{NO}_{2} 18- \\
25 \%\end{array}$ & $\begin{array}{l}\text { Germany as well as } \\
20 \text { other countries }\end{array}$ & $20-30$ \\
\hline Wam & $\begin{array}{l}\text { International and } \\
\text { koloveidekke }\end{array}$ & Foaming (W-B) & Chemical & $\begin{array}{l}2-5 \% \text { water by mass } \\
\text { of hard binder } \\
\mathrm{CO}_{2}: 30-40 \% \\
\text { VOC: } 50-60 \% \\
\mathrm{CO}_{2}, \mathrm{SO}_{2}: 40- \\
60 \%\end{array}$ & $\begin{array}{l}\text { Australia, } \\
\text { Worldwide }\end{array}$ & $100-120$ \\
\hline Evotherm & $\begin{array}{l}\text { Asphalt } \\
\text { innovations }\end{array}$ & chemicaladditives & $\begin{array}{l}0.5 \% \text { of mass of bitumen } \\
\text { emulsion contains } 70 \% \text { of } \\
\text { bitumen }\end{array}$ & $\begin{array}{l}\text { Nox } 60 \% \\
\text { GES: } 60 \% \\
\text { Energy: } 55 \%\end{array}$ & Worldwide & $85-115$ \\
\hline $\begin{array}{l}\text { Low emission } \\
\text { asphalt }\end{array}$ & Lea com fine & Foaming & $3 \%$ water with sand & & $\begin{array}{l}\text { USA, France, Italy, } \\
\text { spain }\end{array}$ & $<100$ \\
\hline Adevera & $\mathrm{PQ}$ & Foaming (W-C) & $0.25 \%$ by total weight of mix & Nox $30 \%$ & USA north America & $10-30$ \\
\hline Revix & $\begin{array}{l}\text { Mathy tech } \\
\text { \&engg services }\end{array}$ & Chemical additives & & & USA & $15-25$ \\
\hline Terex & $\begin{array}{l}\text { Terex road } \\
\text { building }\end{array}$ & Foaming & $\begin{array}{l}2 \% \text { water by mass of bitumen, } \\
\text { anti stripping agent, } 0.2 \% \text { to } \\
0.4 \% \text { by weight }\end{array}$ & & USA & $116-135$ \\
\hline Cecabase & Arkema group & Chemical additives & $2 \%$ by mass of binder & $20 \%$ energy & USA, france & 30 \\
\hline Rediset WMX & AKZO nobel & Chemical additives & $2 \%$ by mass of binder & $20 \%$ energy & USA & $15-25$ \\
\hline Ultra foam GX & $\begin{array}{l}\text { GENCOR } \\
\text { industries }\end{array}$ & Foaming (W-B) & $1-2 \%$ by, mass of bitumen & Energy $50 \%$ & $\begin{array}{l}\text { USA, Netherland, } \\
\text { Italy }\end{array}$ & 90 \\
\hline LT Asphalt & Nynas & Foaming (W-B) & $0.5-1 \%$ by mass of bitumen & Energy $50 \%$ & Netherland & 90 \\
\hline LEAB & $\begin{array}{l}\text { Royal bam } \\
\text { greoup }\end{array}$ & Foaming (W-B) & $\begin{array}{l}0.1 \% \text { by weight ofcoating and } \\
\text { adhension additives }\end{array}$ & Energy $50 \%$ & Germany & $20-30 \%$ \\
\hline Asphaltan B & Romonts & Foaming & $2-4 \%$ by mass of bitumen & Energy $50 \%$ & Germany & $20-30$ \\
\hline Licomont BS & Clariant & $\begin{array}{l}\text { Organic additives } \\
\text { chemical }\end{array}$ & $0.3-.05 \%$ by mass of birtumen & Energy $50 \%$ & germany & 120 \\
\hline $\begin{array}{l}\text { Interlow T } \\
\mathrm{RH}\end{array}$ & $\begin{array}{l}\text { Interchimical } \\
\text { China }\end{array}$ & $\begin{array}{l}\text { Additives polyethylen } \\
\text { Wax based }\end{array}$ & $\begin{array}{l}4 \% \text { by mass of bitumen } \\
4 \% \text { by mass of bitumen }\end{array}$ & Energy $50 \%$ & $\begin{array}{l}\text { italy } \\
\text { China }\end{array}$ & 120 \\
\hline
\end{tabular}

W-C: Water-containing; W-B: Water-based

Dosage Rate of Warm Mix Asphalt Additives

There are some considerations on use of additional chemical additives to enhance adhesion and coating. Organic and chemical additives usually already contain all necessary chemical components, nonetheless use of additional chemical additives may be considered, if relevant. As for foaming technologies, most of the suppliers advise the use of antis tripping additives as summarized in Table 1. However there is a precaution that the lower temperatures used for WMA production may reduce the effectiveness of any chemical antis tripping additives additionally used in the process (11). This should be considered when choosing a specific anti- stripping product.

\section{Styrene Polymers Styrene Butadiene (SBS)}

There are several types of polymers used in bituminous mixes, currently the most commonly used polymers for asphalt modifications is SBS (Styrene Butadiene Styrene) followed by other polymers such as crumb rubber, SBR (Styrene Butadiene Rubber), EVA (Ethylene Vinyl Acetate) and Polyethylene (Sengoz and Isikyakar, 2008) (122).

According to Casda et al 2006, a modified bitumen mix market survey in $2006-200,80 \%$ of states across the country used SBS as a modifier. 
Lavin and baker et al 2003 (86) while evaluating to improve the quality of asphalt pavements, the asphalt industries developed PMA to help to meet the demand for better pavements and to influence better pavement performance under high traffic applications. Polymer modifications are becoming important factors in paving industry due to their proven effects such as better resistance to rutting fatigue damage, stripping and thermal cracking in asphalt pavements of polymer modifiers, Styrene Butadiene Styrene (SBS) originally developed by Shell Chemicals co, is widely used in majority of the asphalt binders industry and probably the most appropriate polymer for asphalt modification, SBS creates three dimensional network within virgin asphalt resulting in excellent bending strength to aggregates which lead to a durable and long lasting pavements.

Rajpal et al, 2005 (114) according to his studies the SBS behaves like elastic rubber at ambient temperatures and it can be processed plastic when heated (thermoplastics elastomer). generally most types of rubber are difficult to process because of their cross linked, SBS and other thermoplastic elastomers can be managed to be rubbey without cross linked, thus making them easy to process into useful shapes. In structural terms its backbone is made upon three segments as shown in figures given below, figure 5 shows polystyrenes as a hard plastic which provides durability at high temperatures, figure 6 shows a scheme of interaction between SBS network and asphalt fraction. It is envisioned that the SBS network interacts with asphalting and resins miscellaneous.

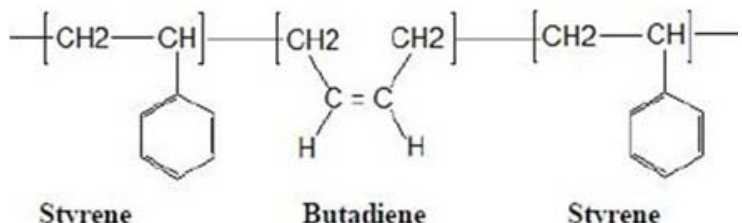

Figure 2. Basic structure of SBS polymer.

\section{Mixing in laboratory}

While it is simple to produce WMA of organic and chemical technologies as it requires only the addition of the right amount of additive, the production of WMA with foaming technologies appears to be complicated when tested in the laboratory. For the water based foaming technologies nozzles and foaming principles are different for each producer and the foaming is strictly related to production process. It may be impossible to repeat such a production and compaction process in the laboratory. No laboratory research that simulates this process was found during literature studies. For other foaming technologies that use wet aggregates, water containing additives or bitumen's of different hardness, the mixing in laboratory may be complicated and may require that conditions are simulated as close as possible to those in a production plant. The moisture content that is proposed in the respective technology must be followed and the sequence of technological operations ensured. One must also use precaution because of the water steam in the process.

The quality and performance of the mix are the same as specified for HMA in IRC: 111 except for mixing and laying temperatures, which are at least $30^{\circ} \mathrm{C}$ less than those specified for HMA. The threshold of $30^{\circ} \mathrm{C}$ is considered technologically feasible as well as desirable from the point of view of fuel savings of some significance. Design of mix, quality of inputs (except the additives) and tests required to be performed follow the same procedures as specified in IRC: 111. In addition, the following WMA specific tests are performed:

1. Coating

2. Compatibility

3. Moisture Sensitivity (IRC: SP: 101-2014)

The above parameters should be verified first in the laboratory, after the criteria are satisfied, a field trial of at least $500 \mathrm{~m}$ length are constructed, and the parameters obtained in the laboratory are verified.

Polymer modified Asphalt (PMA)

(2) Need for Polymer Modified Asphalt

Need for modification of Asphalt: while seeking to improve the quality of asphalt pavements the asphalt industry developed polymer modified asphalt (PMA) to meet the demand for better pavements and to influence better pavement performance under high traffic applications, polymer modifications are becoming important factors in paving industries due to their proven efforts such as better resistance to rutting, fatigue, damage, stripping and thermal cracking in asphalt pavements. (Punith et al, 2005) (110).

Bitumen is normally used as a paving binder all over the field in flexible pavements constructions. Bituminous pavements then properly designed and constructed, perform quite satisfactorily. The other possibility is the use of better materials for pavement constructions out of which the choice of better granular materials like aggregates, sands etc, if available at all will lead to higher cost of transportations from long distance and related problems. Hence the next available alternative is to modify the bitumen in order to improve its properties so that the bitumen mixes containing these modified binders are capable of meeting the requirements of specific situations.

Polymer modified bitumen increases the elasticity of the mix and also increases viscosity at higher temperature. The viscosity helps to limit the deflection while the elastic recovery reduces the residual deformation. The elastic surface layer bridges the cracks from unmodified layers underneath, thus, maintains the water-tight nature of the asphalt and protects the underlying structure.

Rutting resistance

King et al. (61) also carried out a test for testing the rutting resistance and it was found that the PMB was able to withstand 4-10 times more loading cycles before ruts of various specified depths.

Experimental research have showed that polymers provide considerable improvement in the physical properties of binder -aggregate combinations. However, the 79 International journal of Structure \& Civil Engg. Res. 2012, reported that the utility of the dynamic creep test for better prediction of the strain rate in polymer modified bituminous mixes. The rut depths were calculated under the wheel 
loading in the laboratory test track tests. It has been shown that satisfactory correlation between the rates of residual strain and rutting rate exists.

Collins et al. (32) reported that selection of appropriate asphalt is essential to obtain a blend with optimal properties. Improved compatibility leads to many advantages. Further, it has been proved that the effectiveness of the added polymer in terms of elastic recovery dropped from a soft to a hard binder.

Temperature susceptibility

Investigations showed that the addition of polymer not only increases the application temperature range of asphaltic binders but also increases the traffic resistance. Further, it was also discussed that the thermal cracking resistance of a pavement is controlled by the temperature at which the binder reaches a modulus close to its glassy modulus.

Oliver and Tredrea (1997) (101) presented test results of dynamic shear rheometer on PMB. It was found that longterm laboratory exposure at a temperature below the maximum encountered in pavement service resulted in large changes in the rheological behavior of the PMB and these changes were likely to reduce the advantages which fresh PMBs have over unmodified bitumen in service.

Airey and Brown (1998) (7) investigated chemical changes and the rheological of polymer modified bitumen under short-term and long term aging condition. The changes in rheology caused by aging are, decrease in penetration and increase in viscosity \& softening point. It was further concluded that any variation in aging behaviour of the PMB is due to the presence of polymer.

Khattak and Baladi (2001) (79) showed that rheological and engineering properties of polymer mixed binders mixtures largely depend on the polymer type and content. The mix design of the conventional bitumen and polymer mixed bituminous mixtures were conducted using the Marshall mix-design procedures. At the optimum polymer content, the strengths of the polymer modified mixtures were approximately 1.45 times higher than the mixtures made with bitumen binder subjected to the same processing conditions. Further, empirical relations for predicting fatigue life of polymer modified bituminous mix were also developed considering different polymer content, plastic deformation, viscosity and indirect tensile strength.

Khattak and Baladi (2001) (75) also showed the improvement in the resistance to plastic deformation with polymer modification. It is shown that the required number of load cycles to accumulate any value of plastic deformation increases as the polymer content is increased until 5\% optimum polymer content is reached.

Kumar et al (84) carried out study for the properties of polymer modified binder and it has been shown that Styrene Butadiene Styrene (SBS) polymer modified binder has better elastic recovery as compared to Linear Low Density Polyetheylne (LLDPE) binder.

Punith et al. (110) studied the effect of various factors on resilient modulus of elasticity under repeated load indirect tensile tests. These studies were carried out on conventional
80/100 grade bitumen and bitumen modified with polyethylene and crumb rubber separately. It has been shown that the performance of polymer modified bitumen with polyethylene is better than conventional 80/100 grade bitumen and binder modified with crumb rubber.

WMA Mixing and Compaction Temperature

Mixing and paving/compaction are the two main tasks of the asphalt production process, which together determine the quality of material and With the objective of finding new methodologies to determine adequate mixing and compaction temperatures for asphalt production with modified bitumen, several researchers have carried out studies during the last decade on viscosity variation with test conditions and influence of the production temperature on volumetric and mechanical properties. In the hot-mixing method, the processes are highly influenced by the viscosity of the bitumen, which depends on the temperature and the type of bitumen as during mixing, the aggregate coating quality is determined and, during compaction, the ability of aggregate particles to form a compact, resistant, durable, and cohesive structure with designed air void content [1-4] is determined. However, bitumen behavior variability does not explain all variability in asphalt workability.

Construction technical guides do not specify any methodology to determine mixing and compaction temperatures of modified bitumen's, or it simply defines as EN 12697-33 does: "When using modified binder or hard grade bitumen binder or additives, the temperature may be adjusted". Many studies have confirmed that the increase of temperature have serious consequences to modified bitumen's (oxidation, breakdown of long chain polymers, volatile loss, emissions, odor-causing compounds) Arafatyero, et al [8].

Hakseo Kim and Amirkahanian et al 2010 (71) demonstrated in their findings that WMA technology (Aspha-min and sosaobit) can be used to decrease the compaction temperatures of SBS modified asphalt mixtures as compared with HMA mixtures to satisfy the targeted air voids contents. The facts that those WMA mixtures, especially at lower compactions levels showed lower air voids than that of HMA mixtures at lower temperatures indicates that WMA technologies can help in reducing the compaction effort during the initial stages of constructions. The statistical analysis indicates that WMA mixture regarding all engineering properties (TSR, Rutting etc) tested for their works, which indicated that the use of WMA technologies in SBS modified asphalt mixtures did not adversely affect the mixture properties.

National Centre for Asphalt technology (NCAT) has probably conducted more studies of WMA than any other than any other agencies. The US (Hurley and Prowell, 2005a, 2005b, 2006a, 2006b, NCAT 2005) (41, 42, 43). They have demonstrated that aspha-min, Sasobit and Evotherm improve compatibility in the superpave gyratory compactor and reduce air voids by an average of $0.65,0.87$ and 1.5 respectively, over that of the corresponding control mix improved compaction was noted at temperatures as low as 
$190^{\circ} \mathrm{F}$. Addition of aspha-min, Sasobit and Evotherm did not affect the resilient modulus of mixes. Decreased aging due to lower mixing and compacting temperatures may have contributed to lower indirect tensile strength of WMA mixes. Apha-min did not increase rutting potential of mixes while Sasobit and Evotherm generally decreased the rutting of mixes evaluated. The rutting potential increased with decrease in mixing and compaction temperatures, which may be related to decrease aging of the binder.

Warm mix asphalt technologies facilitate compaction. Certain systems have been described as "Flow Improvers" to improve "compact ability" of bituminous mixes even in adverse windy and cold weather conditions. The objective of WMA systems is to modify the temperature/viscosity relationship in a manner such that, suitable mixing and compaction viscosities are achieved at lower temperatures, while Adequate viscosity is maintained at service temperatures.

The bracket of temperatures for laboratory compaction for neat binders is often determined using Temperature/viscosity charts. The recommended optimal neat binder viscosity for compaction is. $28 \pm .03 \mathrm{~Pa}-\mathrm{s}$ ( $280 \pm 30$ centistokes). Compaction time corresponds approximately to the period of time associated with the decrease in temperature between $\sim 140^{\circ} \mathrm{C}$ and $90^{\circ} \mathrm{C}$ for conventional HMA. There are several factors that may contribute to help compaction: a larger temperature bracket for WMA Systems, lower binder viscosity within the compaction temperature bracket and the decreased rate of heat Loss at lower temperatures. It is also suggested that a lubrication effect may also be provided with certain Additives.

\section{Performances of warm mix asphalt mixes}

The performance data collected in Europe and North America is indicating that WMA will perform equally or possibly better than conventional HMA. The oldest WMA pavement was placed in Germany in the mid 90s', while the oldest reported section place in North America has been in service since 2004. Warm mix asphalt is generating a lot of interest worldwide and the research community is decisively at work to provide performance information on various WMA systems. Technical reports are "system specific" but, in general, they all indicate that:

1. Densification of WMA is improved

2. Mixture stiffness is not adversely affected

3. Rutting resistance is not adversely affected

4. Cure time is shorter

5. Binder hardening is less

6. Resistance to thermal cracking may be improved

7. Moisture damage requires specific attention

8. WMA systems may be used with any type of mixes

9. Effect on binder properties is binder and system specific. Moisture damage susceptibility

Stripping is an important performance criterion for any type of bituminous mix. The information obtained on stripping is variable from one WMA system to another. Some reports indicate a slight decrease in Stripping resistance, while other reports are not signifying any trends. The consensus in the research community is that moisture damage may be affected by the reduced mixing temperature and/or the type of additive used. At lower mixing temperature the aggregate internal moisture may not be completely removed, which may affect the stripping resistance of the mixture. Nonetheless, as for any type of bituminous mix, the usage of adhesion agents needs to be considered, whenever stripping is identified as a potential problem.

Moisture damage caused by a loss of bond between the asphalt binder. or the mastic and the aggregate under traffic loading, can result in a decrease of strength and durability in the asphalt mixture and ultimately affect its long-term performance. Moisture damage, in general, in flexible pavements occurs because of the separation and removal of asphalt binder from the aggregate surface in the presence of water, which leads to stripping in the asphalt pavement and potentially causes premature failure In recent years, the asphalt industry has investigated warm asphalt technology as a means of reducing the mixing and compaction temperatures of asphalt mixes and thereby saving energy and reducing emission.

Hamburg wheel tracking tests indicated good performance in terms of moisture susceptibility and rutting for the mixtures containing Sasobit and magnabond as well as the mixture containing sasoflex. During their studies they recommended that moisture sensitivity testing should be conducted at anticipated field production temperatures. If test results Determined are not favorable an anti stripping agent should be added to mix to increase the resistance to moisture.

Feipeng Xiao (139) conducted laboratory investigation of moisture damage in WMA mixtures containing moist aggregates. Indirect tensile strength (ITS), tensile strength ratio, deformation, and toughness tests were performed to determine the mixtures' moisture susceptibilities. The experimental design included two percentages of moisture content $(0 \%$ and $-0.5 \%$ by weight of the dry mass of the aggregate), two WMA additives (Asphamin and Sasobit), and three aggregate sources. In this study $15 \mathrm{mix}$ designs were performed, and 180 specimens were tested. Test results indicated that, as expected, dry ITS values were affected by aggregate moisture and hydrated lime contents, whereas a WMA additive did not signifi- cantly alter the dry ITS and toughness values. Statistical analysis showed no significant differences in the wet ITS values of WMA mixture of three types of mixtures (control, Asphamin, and Sasobit) under identical conditions (same moisture and lime contents). Statistical analysis also showed that wet ITS values, generally, were statistically different for mixtures made with various aggregate sources. The deformation resistance values of mixtures containing moisture were lower than those of mixtures made with dry aggregate. mixtures made with dry aggregate. However, the results indicated that the addition of hydrated lime increased the deformation resistance of all mixtures.

Marshall Properties.

In India Marshall Mix design is the sole methods used for the design of bituminous concrete mixes. This is standard 
laboratory methods used by and large in different parts of the world for determining the strength and flow characteristics of bituminous paving mixes. Research work has been carried out and reported as follows.

Awanti et al 2006, (11) studied influences of modified marshal compaction techniques o engineering properties of polymer modified and neat bituminous concrete mixes and reported about the various laboratory investigations carried out on two types of polymer modified bituminous concrete mixes with SBS copolymer and SBR and neat bituminous concrete mix 80/100 bitumen and studied the effects of adopting modified Marshall compaction technique on engineering properties of optimum binder content and Marshall parameters. Marshall Test results indicated higher stability, higher flow, higher unit weight lower air voids and lower optimum binder content for all mixes compacted with modified Marshall Hammer when compared to standard Marshall Compaction. Static ratio, resilient modulus ratio and fatigue life were found to be higher for mixes compacted with modified compaction when compared with standard Marshall Compaction. Modified compaction shows permanent deformation as well as deformation rate. The performance of polymer modified bituminous concrete mix with SBS polymer is found to be superior when compared to the other two mixes prepared with polymer modified bituminous mixes prepared with polymer modified bitumen with SBR as well as neat bitumen. The optimum binder content were also reduced by 8 percent, $9 \%$ and $1.5 \%$ for PMB-1, PMB-2 and BC mixes compared by modified Marshall compaction when compared to standard Marshall compaction, concluded that this reduction brings substantial economy in PMBC mixes and a marginal economy BC mixes.

Studies on bituminous mixes using natural fiber determined the effects of use of a naturally and local available fiber called SISAL fiber used as a stabilizer in SMA and as an additive in $\mathrm{BC}$. The $\mathrm{BC}$ and SMA mixes were found to be $5 \%$, and $5.2 \%$ respectively. The $\mathrm{BC}$ and SMA mixes prepared at $\mathrm{OBC}$ and OFC were subjected to different performance like drain down test, static indirect tensile strength test and static creep test to evaluate the effects of fiber addition on mix performance. The prepared mixes of SMA and BC were prepared for $60 / 70$ penetration grade bitumen used as binder. OBC and OFC were found out by marshal method of mix design, and by adding $0.3 \%$ of fiber properties of mix were improved. From different tests like drain down test, indirect tensile strength and static creep test it was concluded that SMA with using Sisal fiber gave good results and can be used in flexible pavements. Further it was concluded that addition of SIAAL fiber improved the mix properties like Marshall Stability, drain down test in case of both BC and SMA mixes. It was observed that SMA is better than $\mathrm{BC}$ in respect of tensile strength and creep characteristics.

Kridan et al 2011 (83), The research was perused to investigate and compare the optimum content obtained from two designated mixes (with and without Sasobit additives in fabricating warm mix asphalt specimens in laboratory and to determine the potential to reduce the amount of optimum binder content comparison with control mix to fulfill this purpose two types of mixtures were produced by Marshall method procedure. Both mixers produced at mixing temperature $155^{\circ} \mathrm{C}$ and $135^{\circ} \mathrm{C}$ respectively, the Marshall volumetric properties, bulk density (Gmb), air voids in compacted mix (Av), voids filled with bitumen (VFA) as well as Marshall stability and flow were within investigation to determine the effect of Sasobit additives. The specimen results prepared by Marshall compaction showed significant reduction also showed some decreased in stability whereas, slight increase regarding flow parameter values in saso cases in all bitumen content as well as slight increase in VFA while no change in trend in terms of Gmm, with plotting volumetric values to both mixes versus bitumen content confirmed with requirements set by PWD. The results showed were that the graphs have appeared the optimum content as $4.82 \%$ and $4.78 \%$ to control and Sasobit slight reduction in OPC.

However, the reduction has appeared very slight in optimum bitumen content and difference obtained was $0.04 \%$ and concluded that the difference in OPC can be attributed to mix design methods and compaction pattern.

Soon-jae Lee and Serji N Amirkhanian et al while characterizing short term aging of asphalt binders using gel permeation chromatography and selected super pave binders tests studied both the rolling thin film oven test (RTFOT) and short term oven ageing (STOA) methods to represent the ageing of asphalt binders during plant mixing, transportation and paving. They conducted as an experimental programme and the material was designated as control binds, three SBSmodified binders of PG 76-22 as SM binder and three rubber modified binders. Loose asphalt mixes were obtained from six paving fields' series of gel permeation chromatography (GPC), rotational viscosity (Rave) and dynamic shear (DSR) tests were conducted. From the results obtained they concluded that based on increase in LMS ratios from GPC test the RTFOT method was found to have less effect on binders than the STOA methods for asphalt mixtures in the laboratory. Laboratory ageing methods indicated a good correlation with each other but the ageing effect among the binders which were short term aged in field varied widely. The longer ageing time in RTFOT was found to lead to an increase in high temperature viscosity and in the high failure temperature of asphalt binders, the only exception being rubber modified binders, in which the rubber in asphalt binders. The GPS test for the crumb rubber modified binders in which the rubber in asphalt was removed using a syringe filter was effective in evaluating the ageing effect of rubber modified binders for different RTFOT aging times.

Hakseokim et al 2010 (48) evaluated performance studies on SBS modified asphalt mixtures using warm mix technologies, the main concept was to establish industry standards of using styrene-butadiene-styrene (SBS) modified mixtures and combines it with relatively new warm mix technology (WMA) in order to create more sustainable and eco friendly asphalt paving process. Two WMA technologies, 
microwater (Aspha-min), synthetic wax (Sasobit) based were used to evaluate their effectiveness in SBS modified asphalt mixtures along with binder analysis (including) super pave binder performance and surface topography compaction condition study, oxidative aging analysis and mixture performance analysis. Finally, they concluded that WMA technology (Ashman) and Sasobit can be used to decrease the compaction temperatures of SBS modified asphalt mix as compared with HMA mixtures to satisfy the targeted air voids contents. WMA mixtures at lower compaction levels showed lower air voids in the mix than HMA at lower temperatures.

The statistical analysis indicated that these were no significant difference between HMA and WMA mixtures regarding all engineering properties (like TSR, Rutting etc) tested for this research work, which indicated that use of WMA technologies and SBS modified asphalt mixtures do not adversely affect the mixture properties.

The procedure developed to correlate the engineering properties of materials to the images obtained from AFM showed a good relationship, and suggested a simple way to predict some of the engineering properties.

From the results derived from AFM analysis it was found that addition of alpha-min and Sasobit modified the surface topography of the binder samples. These differences also varied among binder sources as each binder source resulted in different surface images at both the micro and nana scales. The various properties of SBS modified binders were believed to have an influence on the topography results.

Remit et al 1998 (125) evaluated the Marshall stability properties on WMA using zycotherm chemicals additive and studied the Marshall stability values WMA specimens produced at $155^{\circ} \mathrm{C}$ which resulted in having good stability values when compared with HMA specimens prepared at $130^{\circ} \mathrm{C}$ and $115^{\circ} \mathrm{C}$ which showed improvement by the addition of Zycotherm at an additive dosage rate of $0.1 \%$ by weight of binder, the optimum binder content for HMA mix at $155^{\circ} \mathrm{C}$ was found out to be $5.4 \%$ mad WMA mix at $130^{\circ} \mathrm{C}$ and $115^{\circ} \mathrm{C}$ which shows improvement by addition of zycotherm at an additive dosage rate of $0.1 \%$ by weight of binder, optimum binder content for $\mathrm{HMA}$ mix at $155^{\circ} \mathrm{C}$ was found out to be $5.4 \%$ and WMA mix at $130^{\circ} \mathrm{C}$ with $0.1 \%$ of zycotherm was found out to be $5.37 \%$ which concluded that optimum binder content of HMA and WMA mix were different with varying temperatures and additives dosage rate so that optimum binder content was found out individually for both HMA and WMA mix for varying temperatures and additive dosage rates.

Mahabir Panda et al 1995 (104) determined certain relevant properties like viscosity, temperature susceptibility, hardening of binder etc, the mixing and compaction temperature of aged and virgin percentage of WMA chemical tests are to be carried out on modified and unmodified bitumen at the mixing conditions for preparations of binders once these are fixed and determine and determined relevant properties like viscosity, temperature susceptibility, hardening of binder etc can be fixed, Panda et al in his research work reported that the minimum values of mixing parameters namely temperature and time of mixing and speed of the sample of PMB produced during trials. The minimum temperature can be found out in order to assess the effects of changes in temperatures and times of blending to the properties of binders the sample are prepared with various percentages of binder the sample are prepared with various percentages of the polymers binders by weight at varying temperatures and time of blending and testing for some of their physical properties namely penetration, softening point, ductility and specific gravity were tested. In ordered to verify the reliability the procedures to produce the binder with reliability of procedure of binder with uniform properties identical blends has to be prepared for each type of polymers and tested for their properties.

Pcyman Aghazedeh et al 2014 (119) considered the WMA technology as energy efficiency and environmental susceptibility, proposed to consider the service life of these types of pavements. While evaluating the effects of WMA additives on aging characteristics of bituminous mixtures. The results showed conventional bitumen tests indicated the increase in softening point and reduction in temperature susceptibility determined by penetration index of the bitumen samples involving WMA additives. Lower values of penetration index indicated higher temperature susceptibility. The addition of WMA additives decreased the retained P.I value of bitumen samples which simulated the ageing of bitumen during mixing of aggregates, which indicated that the addition of WMA additives was less affected during short term ageing. WMA exhibited better performance than conventional HMA, in over all evaluation taking into consideration the defined indices.

Fatigue behavior of asphalt mixtures (PMB and SBS)

Various parameters can affect fatigue behavior of asphalt mixtures. Generally, effective parameters on fatigue life consist of thickness of asphalt layer, loading amplitude, shape and frequency of loading, rest period in loading, compression, and characteristics of asphalt mixtures such as sieve analysis of fine and coarse aggregates, type of the bitumen, stiffness of mixture, environmental conditions and additives.

Awanti et al 2006 (11) in his research on fatigue behavior of polymer modified and neat bituminous mixes using modified Marshall specimens, from their experimental work and subsequent material used, characterized the neat and polymer modified bituminous binder and specifically concluded that softening point and viscosity values found to be higher by 16 and $98 \%$ for PMB-SBS when compared to neat bitumen. Elastic recovery showed higher flexibility and higher deformation resistance of pmb compared to pmb-sbr mixing and compaction temperatures for pmb binders were $150-170^{\circ} \mathrm{C}$ respectively, for neat bitumen these values were $150-138^{\circ} \mathrm{C}$ respectively. Fatigue lives have been decreased for PMBC-1-ML-M and BG-ML-M mixes. The reduction in fatigue lives with increase in air voids for BG-ML-M -M at higher stress level is of much higher magnitude when compared to PMBC-1-ML-M mixes. The fatigue life of PMBC-1-ML-M mix was 1.82 times higher when compared 
to BG-ML-M. Modified Marshall Compaction increased the resistance to permanent deformation when compared to standard Marshall Compaction. The performance of PMBC1 mix showed superior results when compared to $\mathrm{BC}$ mix at all temperatures. Moisture susceptibility found to be reduced by using modified Marshall compaction to standard Marshall Compaction, due to improved comp active efforts, which resulted in lower moisture penetration and that led to higher TSR and MRR. polymer modified and neat bituminous mixes prepared using middle limits gradation showed lowest moisture susceptibility when compared to upper and lower gradation limits.

According to the results of strain controlled tests using four-point bending beam, as the loading frequency increases, fatigue life of conventional samples decreases which seems to be the result of decrease in time for self healing of the materials (Baburamani, 1999). Loading frequency is employed for simulating different traveling speed of moving vehicle in four-point flexural beam test. As the traffic speed increases, the loading frequency increases (Mollenhauer, Wistuba \& Rabe, 2009).

\section{Materials and Methods}

Methodology Flow Chart

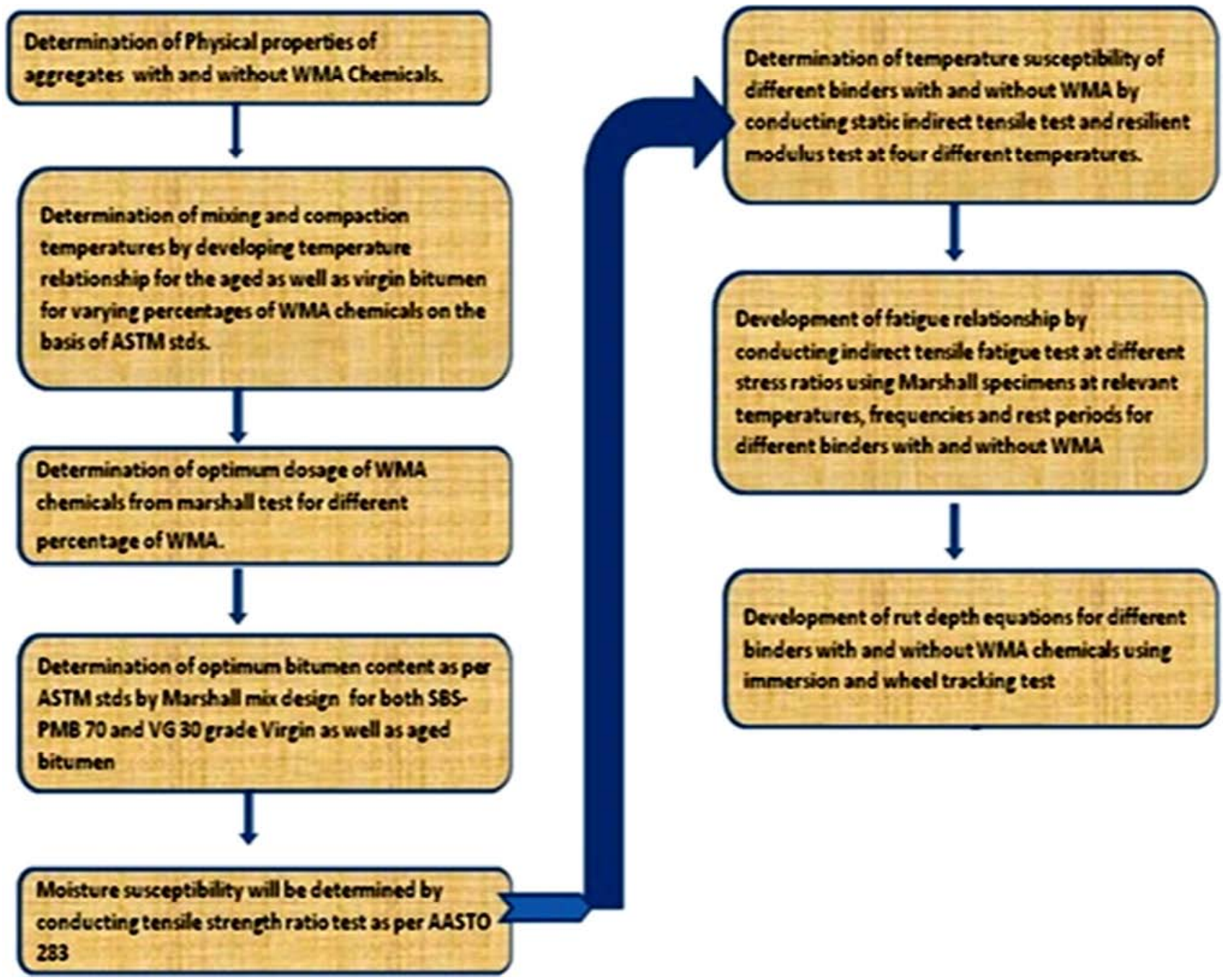

Figure 3. Methodology Flow Chart.

\section{Materials Used}

Aggregate of $20 \mathrm{~mm}$ down, $12.5 \mathrm{~mm}$ and down, $6 \mathrm{~mm}$ and down and dust $(75 \mu$ passing).

Binders Used

Neat bitumen: VG-30 Grade

Polymer modified binder: polymer modified binder of 70 grades with styrene butadiene styrene (SBS-PMB-40), for modifications $70 / 100$ penetration grade bitumen $\mathrm{s}$ used. as per the suppliers (Hindustan colas limited tamilnadu)

WMA Additives Used

WMA Additives: Zycotherm, Sasobit andEvotherm 
Table 2. Laboratory tests results of aggregates.

\begin{tabular}{|c|c|c|c|}
\hline Material & Property tested & Value & Requirements \\
\hline \multirow{6}{*}{$\begin{array}{l}\text { Coarse sieves aggregate } \\
\text { (passing } 26 \mathrm{~mm} \text {, retained on } \\
2.36 \mathrm{~mm} \text { sieve) and } \\
\text { Fineaggregates (passing } \\
(2.36 \mathrm{~mm} \text {, retained on } \\
0.075 \mathrm{~mm})\end{array}$} & Specific gravity & 2.80 & \multirow{6}{*}{$\begin{array}{l}\text { IS 2386- Part III } \\
2.5-3 \\
\text { (IS 2386-Part IV) } \\
\text { Max 35\% } \\
\text { (IS 2386-Part IV) } \\
\text { Max 27\% } \\
\text { (IS 2386-Part IV) } \\
\text { Max 45\% } \\
\text { (IS 2386-part IV) } \\
\text { Max 35\% } \\
\text { (IS2386 Part III) } \\
\text { Max 2\% }\end{array}$} \\
\hline & Los Angeles abrasion value & $43.52 \%$ & \\
\hline & Aggregate impact value & $10.29 \%$ & \\
\hline & Aggregate crushing value & $39.78 \%$ & \\
\hline & Flakiness and Elongation index & $\begin{array}{l}45.33 \% \\
34.6 \%\end{array}$ & \\
\hline & Water absorption & $0.50 \%$ & \\
\hline
\end{tabular}

Coarse Aggregates and Fine Aggregates

According to IS 383: 1963 aggregates which are retained on $4.75 \mathrm{~mm}$ IS sieve is defined as coarse aggregate and which are passing through $4.7-5.75 \mathrm{~mm}$ IS sieve is defined as fineaggregates. the ministry of road transport and highways (MORTH) recommended gradation as per nominal size of aggregates $19 \mathrm{~mm}$ for DBM. the laboratory tests results of aggregates have been given in table 2 .

Table 3. Aggregate sieve analysis.

\begin{tabular}{lll}
\hline IS sieves $(\mathbf{m m})$ & \%Passing obtained & \%Passing Range (Grade-2) for DBMas per MORTH \\
\hline 19 & 100 & 100 \\
13.2 & 89.06 & $79-100$ \\
9.5 & 78.06 & $70-88$ \\
4.75 & 65.05 & $53-71$ \\
2.36 & 50.51 & $42-58$ \\
1.18 & 41.88 & $34-48$ \\
0.6 & 31.19 & $26-38$ \\
0.3 & 20.12 & $18-28$ \\
0.15 & 10.47 & $12-20$ \\
0.075 & 5.08 & $4-10$ \\
\hline
\end{tabular}

\subsection{Gradation Curve}

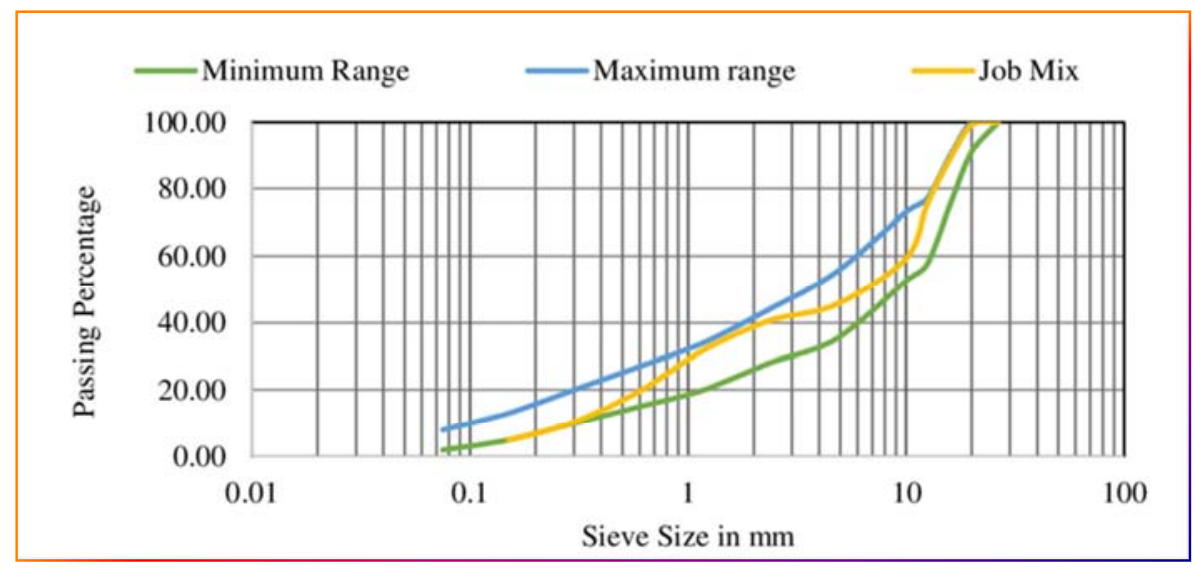

Figure 4. Sieve size vs\%finer.

Table 4. Properties of Neat Bitumen VG-30 and SBS-PMB-40.

\begin{tabular}{|c|c|c|c|c|c|}
\hline \multirow[b]{2}{*}{ Sl.no } & \multirow[b]{2}{*}{ Property } & \multicolumn{2}{|l|}{ Results } & \multicolumn{2}{|l|}{ Requirements of } \\
\hline & & SBS-PMB-40 & Neat bitumen VG-30 & $\begin{array}{l}\text { VG-30neat bitumen } \\
\text { (IRC: SP: 53-2002) }\end{array}$ & $\begin{array}{l}\text { SBS-PMB-40 } \\
\text { (ASPER IS: 73-1992) }\end{array}$ \\
\hline 1 & Penetration at $25^{\circ} \mathrm{C}$ & 47.66 & 66.33 & $50-90$ & $60-100$ \\
\hline 2 & Ductility at $27^{\circ} \mathrm{C}$ & 100 & 100 & 60 & $75 \mathrm{MIN}$ \\
\hline 3 & Specific gravity, $27^{\circ} \mathrm{C}$ & 1.04 & 1.04 & -- & $0.99 \mathrm{MIN}$ \\
\hline 4 & Softening point, $\mathrm{R} \& \mathrm{~B}^{\circ} \mathrm{C}$ & $57^{\circ} \mathrm{C}$ & $47.5^{\circ} \mathrm{C}$ & 3 & 3 \\
\hline 5 & Fire point & $260^{\circ} \mathrm{C}$ & $210^{\circ} \mathrm{C}$ & $220 \mathrm{MIN}$ & $175 \mathrm{MIN}$ \\
\hline
\end{tabular}




\section{Marshall Mix Design}

Preparation of Marshall Specimens

Appropriate quantities of mineral aggregates comprising of course aggregates, fine aggregates and mineral fillers such as stone dust were mixed according to gradation selected (tab). the mineral aggregates and binder were heated separately. Aggregates were heated to temperature of about $10^{\circ} \mathrm{C}$ higher than the corresponding mixing temperature of binder. Required quantity of binder was added to the aggregates and mixing was done at a mixing temperature till aggregates were coated uniformly. Marshall Mould, base plate, and compaction hammer were heated to compaction temperatures before the mix was placed in the mould. Care was being taken to avoid segregation of the mix placed in the mould. The mix was prodded 20times with heated spatula around the perimeter and 10 times on the rest of surface leaving slightly convex surface. The heated hammer was placed in position and mix was compacted by application of number of blows required for compaction method adopted. After the specimens were cooled to room temperature, they were extracted from the moulds. Blend Proportion

\section{Blend proportion=0.23A $+0.30 \mathrm{~B}+0.16 \mathrm{C}+0.31 \mathrm{D}$ (for VG-30 and SBS-PMB-40) Mixing and Compaction Temperature}

Mixing and compaction temperature for $V G 30$ grade bitumen

According to Hensley (1998), mixing temperature can be defined as that temperature, which produces a uniform and sufficient coating of the coarse aggregates, which is to be estimated on the basis of experience. Based on several trails, mixing temperature for plane bitumen was found to be $160^{\circ} \mathrm{C}$ and the compaction temperature was taken as $150^{\circ} \mathrm{C}$. When the WMA (Zycotherm) was added the mixing and compaction temperature of the mix is reduced to $10^{\circ} \mathrm{C}, 20^{\circ} \mathrm{C}, 30^{\circ} \mathrm{C}$ and $40^{\circ} \mathrm{C}$. The amount of WMA added to the mix is $0.1 \%$ of the bitumen content and then the mix is heated and stirred till the bitumen is coated completely to the aggregates. After the aggregates are completely coated with bitumen then the mix is poured into the mould and the compaction is done by giving 75 blows on the either sides of the mould by the hammer.

\section{Results and Discussions}

Table 5. Marshall properties of VG-30 mix at different mixing temperatures.

\begin{tabular}{|c|c|c|c|c|c|c|c|c|c|c|c|c|}
\hline \multirow{2}{*}{ s.no } & \multirow{2}{*}{ sample } & \multirow{2}{*}{ mix.temp } & \multirow{2}{*}{ CompTemp } & \multirow{2}{*}{$\begin{array}{l}\text { Mean } \\
\text { height }\end{array}$} & \multicolumn{2}{|c|}{ Weight of sample (gm) } & \multirow{2}{*}{$\begin{array}{l}\text { Bulk Density } \\
\text { (Gb) }\end{array}$} & \multirow{2}{*}{$\begin{array}{l}\text { Theoretical } \\
\text { Density (Gt) }\end{array}$} & \multirow{2}{*}{$\begin{array}{l}\text { Vv } \\
\text { in } \%\end{array}$} & \multirow{2}{*}{$\begin{array}{l}\text { Vb } \\
\text { in } \%\end{array}$} & \multirow{2}{*}{$\begin{array}{l}\text { VMA } \\
\text { in } \% \\
\end{array}$} & \multirow{2}{*}{$\begin{array}{l}\text { VFB mix } \\
\text { in } \%\end{array}$} \\
\hline & & & & & Air & Water & & & & & & \\
\hline \multirow{3}{*}{1} & VG 30 & 160 & 150 & 5.77 & 1166 & 700 & 2.50 & 2.57 & 2.72 & 13.16 & 15.88 & 82.87 \\
\hline & VG 30 & 160 & 150 & 5.95 & 1213 & 746 & 2.54 & 2.57 & 1.17 & 13.37 & 14.54 & 91.95 \\
\hline & VG 30 & 160 & 150 & 5.97 & 1206 & 732 & 2.53 & 2.57 & 1.55 & 13.31 & 14.86 & 89.56 \\
\hline \multirow{3}{*}{2} & VG 30 & 140 & 130 & 6.22 & 1185 & 720 & 2.54 & 2.57 & 1.16 & 13.36 & 14.53 & 91.94 \\
\hline & VG 30 & 140 & 130 & 6.05 & 1213 & 734 & 2.53 & 2.57 & 1.55 & 13.31 & 14.86 & 89.95 \\
\hline & VG 30 & 140 & 130 & 6.47 & 1260 & 760 & 2.52 & 2.57 & 1.94 & 13.26 & 15.2 & 87.23 \\
\hline \multirow[t]{2}{*}{3} & VG 30 & 120 & 110 & 6.32 & 1247 & 752 & 2.51 & 2.57 & 2.33 & 13.21 & 15.54 & 85.00 \\
\hline & VG 30 & 120 & 110 & 6.37 & 1272 & 780 & 2.48 & 2.57 & 3.50 & 13.05 & 16.55 & 78.85 \\
\hline
\end{tabular}

Table 6. Marshall Properties for SBS-PMB-40at Different Mixing Temperatures.

\begin{tabular}{|c|c|c|c|c|c|c|c|c|c|c|c|c|}
\hline \multirow{2}{*}{ s.no } & \multirow{2}{*}{ Sample } & \multirow{2}{*}{$\begin{array}{l}\text { mix. } \\
\text { temp }\end{array}$} & \multirow{2}{*}{$\begin{array}{l}\text { Comp } \\
\text { Temp }\end{array}$} & \multirow{2}{*}{$\begin{array}{l}\text { Mean } \\
\text { height }\end{array}$} & \multicolumn{2}{|c|}{ Weight of sample (gm) } & \multirow{2}{*}{$\begin{array}{l}\text { Bulk } \\
\text { Density (Gb) }\end{array}$} & \multirow{2}{*}{$\begin{array}{l}\text { Theoretical } \\
\text { Density (Gt) }\end{array}$} & \multirow{2}{*}{$\begin{array}{l}\text { Vv } \\
\text { in \% }\end{array}$} & \multirow{2}{*}{$\begin{array}{l}\mathrm{Vb} \\
\text { in } \%\end{array}$} & \multirow{2}{*}{$\begin{array}{l}\text { VMA } \\
\text { in } \%\end{array}$} & \multirow{2}{*}{$\begin{array}{l}\text { VFBmi } \\
x \text { in } \%\end{array}$} \\
\hline & & & & & Air & Water & & & & & & \\
\hline \multirow{4}{*}{1} & SBS-PMB 40plain & 190 & 170 & 6.05 & 1234 & 740 & 2.32 & 2.54 & 5.10 & 14.36 & 16.36 & 87.77 \\
\hline & SBS-PMB 40plain & 190 & 170 & 6.27 & 1230 & 730 & 2.38 & 2.54 & 5.25 & 14.19 & 17.44 & 81.36 \\
\hline & SBS-PMB 40plain & 190 & 170 & 6.12 & 1232 & 736 & 2.32 & 2.54 & 6.36 & 14.30 & 16.71 & 85.57 \\
\hline & & & & & & & & & 5.57 & 14.28 & 16.84 & 84.9 \\
\hline \multirow{5}{*}{2} & SBS-PMB 40plain & 180 & 170 & 6.05 & 1234 & 740 & 2.49 & 2.54 & 2.00 & 14.36 & 16.36 & 87.77 \\
\hline & SBS-PMB 40plain & 180 & 170 & 6.05 & 1234 & 740 & 2.49 & 2.54 & 2.00 & 14.36 & 16.36 & 87.77 \\
\hline & SBS-PMB 40plain & 180 & 170 & 6.27 & 1230 & 730 & 2.46 & 2.54 & 3.25 & 14.19 & 17.44 & 81.36 \\
\hline & SBS-PMB 40plain & 180 & 170 & 6.12 & 1232 & 736 & 2.48 & 2.54 & 2.41 & 14.30 & 16.71 & 85.57 \\
\hline & & & & & & & & & 2.55 & 14.28 & 16.84 & 84.9 \\
\hline \multirow{4}{*}{3} & SBS-PMB 40 & 160 & 150 & 6.3 & 1218 & 726 & 2.47 & 2.54 & 2.83 & 14.25 & 17.08 & 83.43 \\
\hline & SBS-PMB 40 & 160 & 150 & 6.4 & 1267 & 758 & 2.48 & 2.54 & 2.41 & 14.30 & 16.71 & 85.57 \\
\hline & SBS-PMB 40 & 160 & 150 & 6.47 & 1252 & 752 & 2.50 & 2.54 & 1.6 & 14.42 & 16.02 & 90.01 \\
\hline & & & & & & & & & 2.28 & 14.32 & 16.60 & 86.33 \\
\hline \multirow{4}{*}{4} & SBS-PMB 40 & 140 & 130 & 6.35 & 1247 & 740 & 2.45 & 2.54 & 3.67 & 14.13 & 17.8 & 79.38 \\
\hline & SBS-PMB 40 & 140 & 130 & 6.3 & 1242 & 746 & 2.50 & 2.54 & 1.6 & 14.42 & 16.02 & 90.01 \\
\hline & SBS-PMB 40 & 140 & 130 & 6.3 & 1226 & 732 & 2.48 & 2.54 & 2.41 & 14.30 & 16.71 & 85.57 \\
\hline & & & & & & & & & 2.56 & 14.48 & 16.84 & 84.98 \\
\hline
\end{tabular}


Table 7. Volumetric Properties of VG30.

\begin{tabular}{|c|c|c|c|c|c|c|c|c|c|c|}
\hline \multirow{2}{*}{ Sample No. } & \multirow{2}{*}{$\begin{array}{l}\text { Bitumen } \\
\text { content } \%\end{array}$} & \multirow{2}{*}{$\begin{array}{l}\text { Mean } \\
\text { height }\end{array}$} & \multicolumn{2}{|c|}{ Weight of sample (gm) } & \multirow{2}{*}{$\begin{array}{l}\text { Bulk Density } \\
\text { (Gb) }\end{array}$} & \multirow{2}{*}{$\begin{array}{l}\text { Theoretical } \\
\text { Density (Gt) }\end{array}$} & \multirow{2}{*}{$\begin{array}{l}\text { Vv } \\
\text { in } \%\end{array}$} & \multirow{2}{*}{$\begin{array}{l}\text { Vb } \\
\text { in \% }\end{array}$} & \multirow{2}{*}{$\begin{array}{l}\text { VMA } \\
\text { in \% }\end{array}$} & \multirow{2}{*}{$\begin{array}{l}\text { VFBmix } \\
\text { in \% }\end{array}$} \\
\hline & & & Air & Water & & & & & & \\
\hline \multirow[t]{4}{*}{1.} & 5 & 6.05 & 1090 & 650 & 2.474 & 2.6 & 4.84 & 10.83 & 15.67 & 69.11 \\
\hline & 5 & 6.45 & 1196 & 712 & 2.471 & 2.6 & 4.96 & 10.83 & 15.79 & 68.58 \\
\hline & 5 & 6.6 & 1232 & 734 & 2.473 & 2.6 & 4.88 & 10.83 & 15.71 & 68.93 \\
\hline & & & & & 2.47 & & 4.89 & 10.83 & 15.72 & 68.87 \\
\hline \multirow[t]{4}{*}{2.} & 5.5 & 6.32 & 1227 & 736 & 2.5 & 2.59 & 3.474 & 12.06 & 15.53 & 77.65 \\
\hline & 5.5 & 6.25 & 1144 & 688 & 2.508 & 2.59 & 3.47 & 12.06 & 15.53 & 77.65 \\
\hline & 5.5 & 6.5 & 1217 & 732 & 2.509 & 2.59 & 3.47 & 12.06 & 15.53 & 77.65 \\
\hline & & & & & 2.50 & & 3.47 & 12.06 & 15.53 & 77.65 \\
\hline \multirow[t]{4}{*}{3.} & 6 & 6.37 & 1262 & 759 & 2.50 & 2.57 & 2.72 & 13.16 & 15.88 & 82.87 \\
\hline & 6 & 6.27 & 1247 & 750 & 2.51 & 2.57 & 2.331 & 13.21 & 15.54 & 85.0 \\
\hline & 6 & 6.45 & 1257 & 757 & 2.51 & 2.57 & 2.331 & 13.2 & 15.54 & 85.0 \\
\hline & & & & & 2.513 & & 2.46 & 13.12 & 15.65 & 84.29 \\
\hline \multirow[t]{4}{*}{4.} & 6.5 & 6.42 & 1270 & 758 & 2.48 & 2.56 & 3.125 & 14.14 & 17.26 & 81.92 \\
\hline & 6.5 & 6.325 & 1249 & 745 & 2.48 & 2.56 & 3.125 & 14.14 & 17.26 & 81.92 \\
\hline & 6.5 & 6.325 & 1237 & 740 & 2.49 & 2.56 & 2.73 & 14.19 & 16.92 & 83.86 \\
\hline & & & & & 2.483 & & 2.33 & 14.15 & 17.15 & 82.56 \\
\hline
\end{tabular}

Table 8. Volumetric Properties ofSBS-PMB 40 Grade.

\begin{tabular}{|c|c|c|c|c|c|c|c|c|c|c|}
\hline \multirow{2}{*}{$\begin{array}{l}\text { Sample } \\
\text { No. }\end{array}$} & \multirow{2}{*}{$\begin{array}{l}\text { Bitumen } \\
\text { content } \%\end{array}$} & \multirow{2}{*}{$\begin{array}{l}\text { Mean } \\
\text { height }\end{array}$} & \multicolumn{2}{|c|}{ Weight of sample (gm) } & \multirow{2}{*}{ Bulk Density (Gb) } & \multirow{2}{*}{$\begin{array}{l}\text { Theoretical } \\
\text { Density (Gt) }\end{array}$} & \multirow{2}{*}{$\begin{array}{l}\text { Vv } \\
\text { in\% }\end{array}$} & \multirow{2}{*}{$\begin{array}{l}\text { Vb } \\
\text { in \% }\end{array}$} & \multirow{2}{*}{$\begin{array}{l}\text { VMA } \\
\text { in } \%\end{array}$} & \multirow{2}{*}{$\begin{array}{l}\text { VFBmix } \\
\text { in } \%\end{array}$} \\
\hline & & & Air & Water & & & & & & \\
\hline \multirow[t]{4}{*}{1.} & 5 & 6.5 & 1100 & 653 & 2.46 & 2.58 & 4.65 & 11.83 & 16.48 & 71.78 \\
\hline & 5 & 6.625 & 1095 & 650 & 2.46 & 2.58 & 4.65 & 11.83 & 16.48 & 71.78 \\
\hline & 5 & 6.575 & 1099 & 653 & 2.46 & 2.58 & 4.65 & 11.83 & 16.48 & 71.78 \\
\hline & & & & & 2.46 & & 4.65 & 11.83 & 16.48 & 71.78 \\
\hline \multirow[t]{4}{*}{2.} & 5.5 & 6.55 & 1232 & 739 & 2.5 & 2.56 & 2.34 & 13.22 & 15.56 & 84.96 \\
\hline & 5.5 & 6.6 & 1222 & 735 & 2.51 & 2.56 & 1.95 & 13.27 & 15.22 & 87.18 \\
\hline & 5.5 & 6.6 & 1230 & 738 & 2.5 & 2.56 & 2.34 & 13.22 & 15.56 & 84.96 \\
\hline & & & & & 2.50 & & 2.21 & 13.23 & 15.44 & 85.70 \\
\hline \multirow[t]{4}{*}{3.} & 6 & 6.27 & 1257 & 757 & 2.514 & 2.54 & 1.18 & 13.27 & 14.45 & 91.83 \\
\hline & 6 & 6.3 & 1227 & 739 & 2.51 & 2.54 & 1.18 & 13.27 & 14.45 & 91.83 \\
\hline & 6 & 6.5 & 1231 & 740 & 2.51 & 2.54 & 1.18 & 13.27 & 14.45 & 91.83 \\
\hline & & & & & 2.51 & & 1.18 & 13.27 & 14.45 & 91.83 \\
\hline \multirow[t]{4}{*}{4.} & 6.5 & 6.225 & 1123 & 670 & 2.48 & 2.52 & 1.59 & 15.5 & 17.09 & 90.69 \\
\hline & 6.5 & 6.375 & 1220 & 730 & 2.49 & 2.52 & 1.19 & 15.56 & 16.75 & 92.89 \\
\hline & 6.5 & 6.27 & 1222 & 729 & 2.49 & 2.52 & 1.59 & 15.5 & 17.09 & 90.69 \\
\hline & & & & & 2.48 & & 1.45 & 15.52 & 16.97 & 91.42 \\
\hline
\end{tabular}

Table 9. Stability Test on VG 30 Grade Bitumen.

\begin{tabular}{|c|c|c|c|c|c|c|c|}
\hline Sl. No & $\begin{array}{l}\text { Bitumen } \\
\text { Content }\end{array}$ & Mean Height & $\begin{array}{l}\text { Flow dial } \\
\text { reading }\end{array}$ & $\begin{array}{l}\text { Flow value } \\
(\mathrm{mm})\end{array}$ & $\begin{array}{l}\text { Proving ring } \\
\text { reading }\end{array}$ & $\begin{array}{l}\text { Correction } \\
\text { factor }\end{array}$ & $\begin{array}{l}\text { Corrected } \\
\text { stability }(\mathrm{KN})\end{array}$ \\
\hline \multirow{4}{*}{1.} & $5 \%$ & 6.05 & 350 & 3.5 & 190 & 0.943 & 11.01 \\
\hline & $5 \%$ & 6.45 & 350 & 3.5 & 160 & 0.975 & 9.59 \\
\hline & $5 \%$ & 6.6 & 380 & 3.8 & 150 & 1.083 & 9.99 \\
\hline & & & & 3.6 & & & 10.19 \\
\hline \multirow{4}{*}{2.} & $5.5 \%$ & 6.32 & 390 & 3.9 & 170 & 0.962 & 10.05 \\
\hline & $5.5 \%$ & 6.25 & 380 & 3.8 & 170 & 1.025 & 10.79 \\
\hline & $5.5 \%$ & 6.5 & 400 & 4.0 & 230 & 1.007 & 14.24 \\
\hline & & & & 3.9 & & & 11.66 \\
\hline \multirow{4}{*}{3.} & $6 \%$ & 6.37 & 460 & 4.6 & 286 & 1.007 & 17.71 \\
\hline & $6 \%$ & 6.27 & 420 & 4.2 & 270 & 1.007 & 16.72 \\
\hline & $6 \%$ & 6.45 & 440 & 4.0 & 210 & 0.982 & 12.68 \\
\hline & & & & 4.4 & & & 15.70 \\
\hline \multirow{4}{*}{4.} & $6.5 \%$ & 6.42 & 460 & 4.6 & 210 & 0.975 & 12.59 \\
\hline & $6.5 \%$ & 6.325 & 470 & 4.7 & 220 & 1.02 & 13.80 \\
\hline & $6.5 \%$ & 6.325 & 480 & 4.8 & 240 & 0.997 & 14.79 \\
\hline & & & & 4.9 & & & 13.7 \\
\hline
\end{tabular}




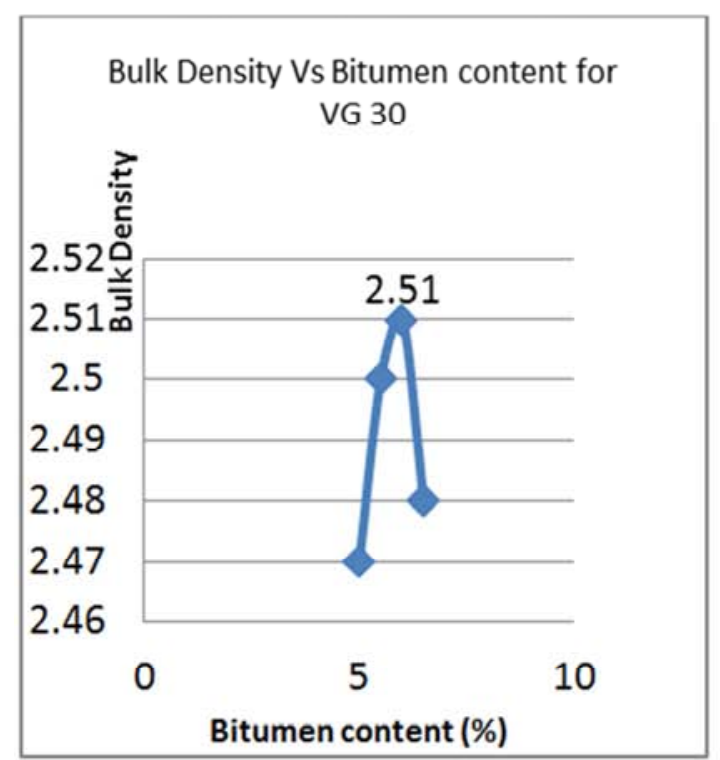

VMA Vs Bitumen content For VG $\mathbf{3 0}$
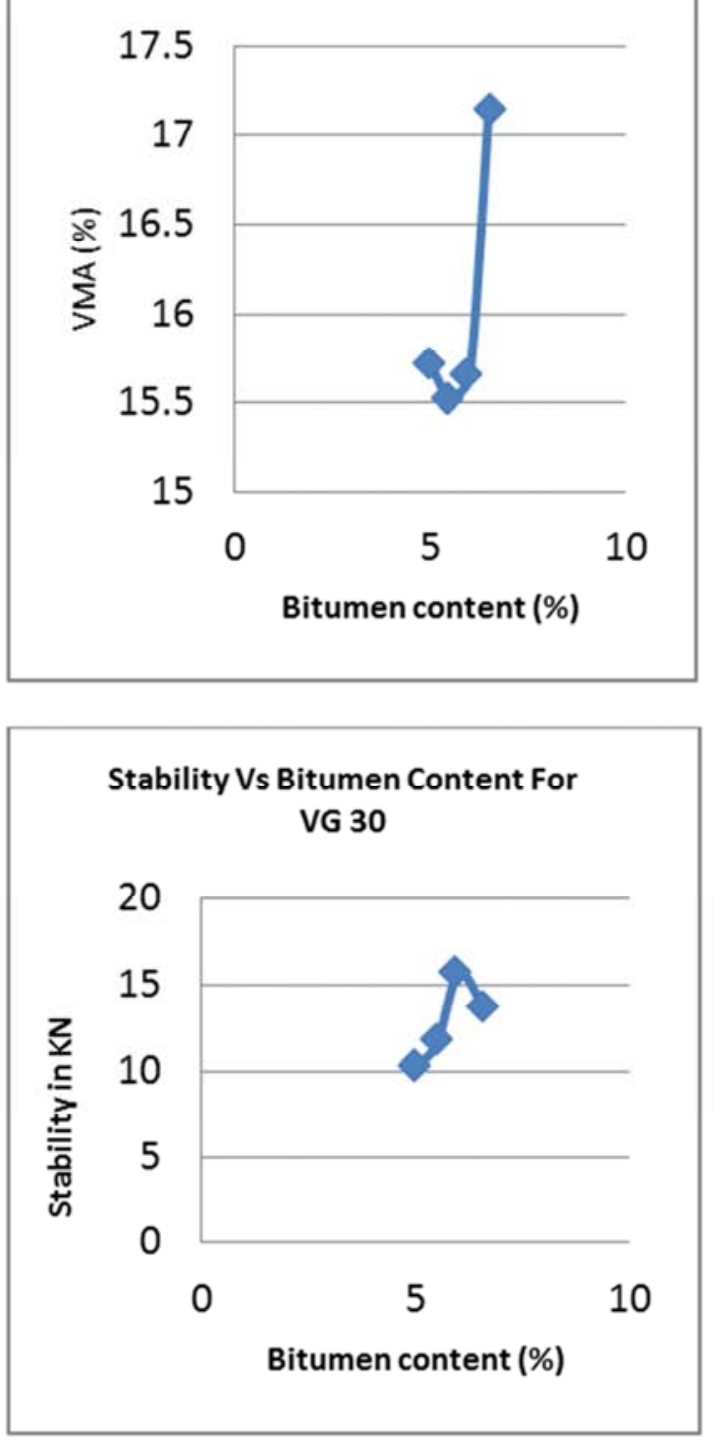

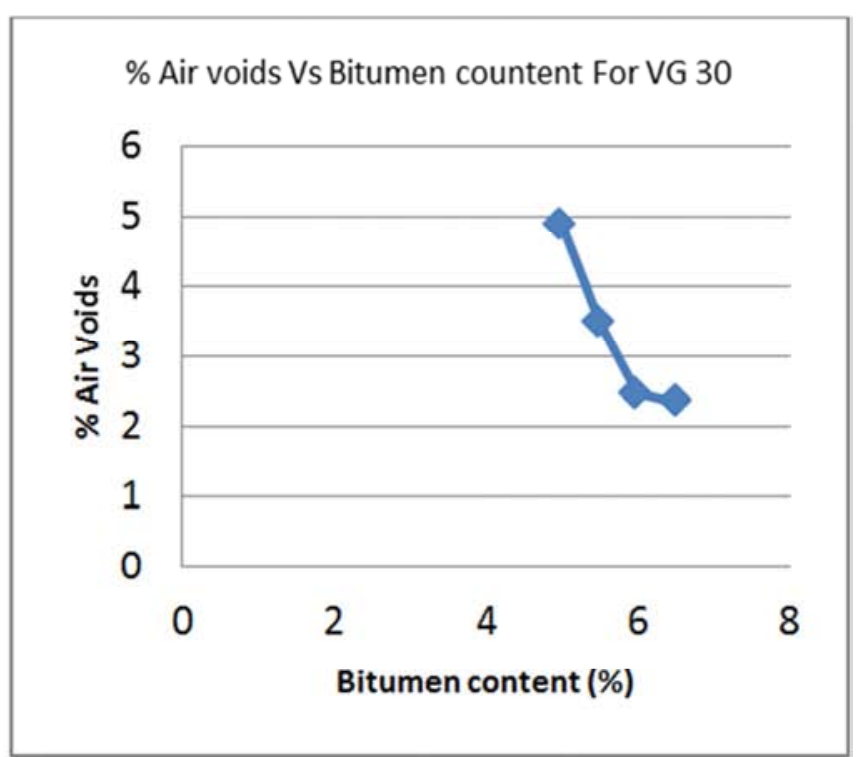

VFB Vs bitumen content For VG 30

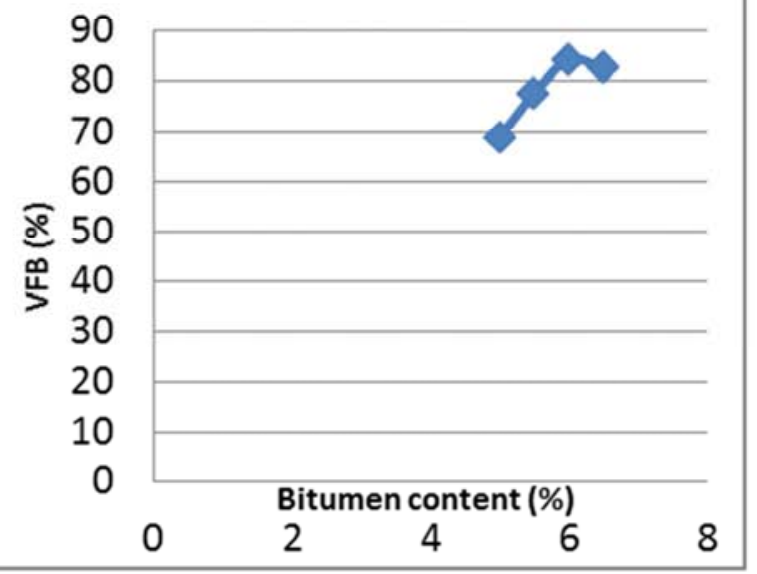

Flow Vs Bitumen Content for VG 30

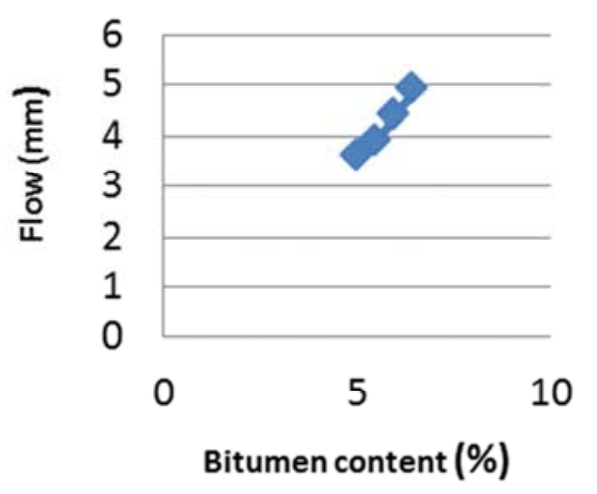



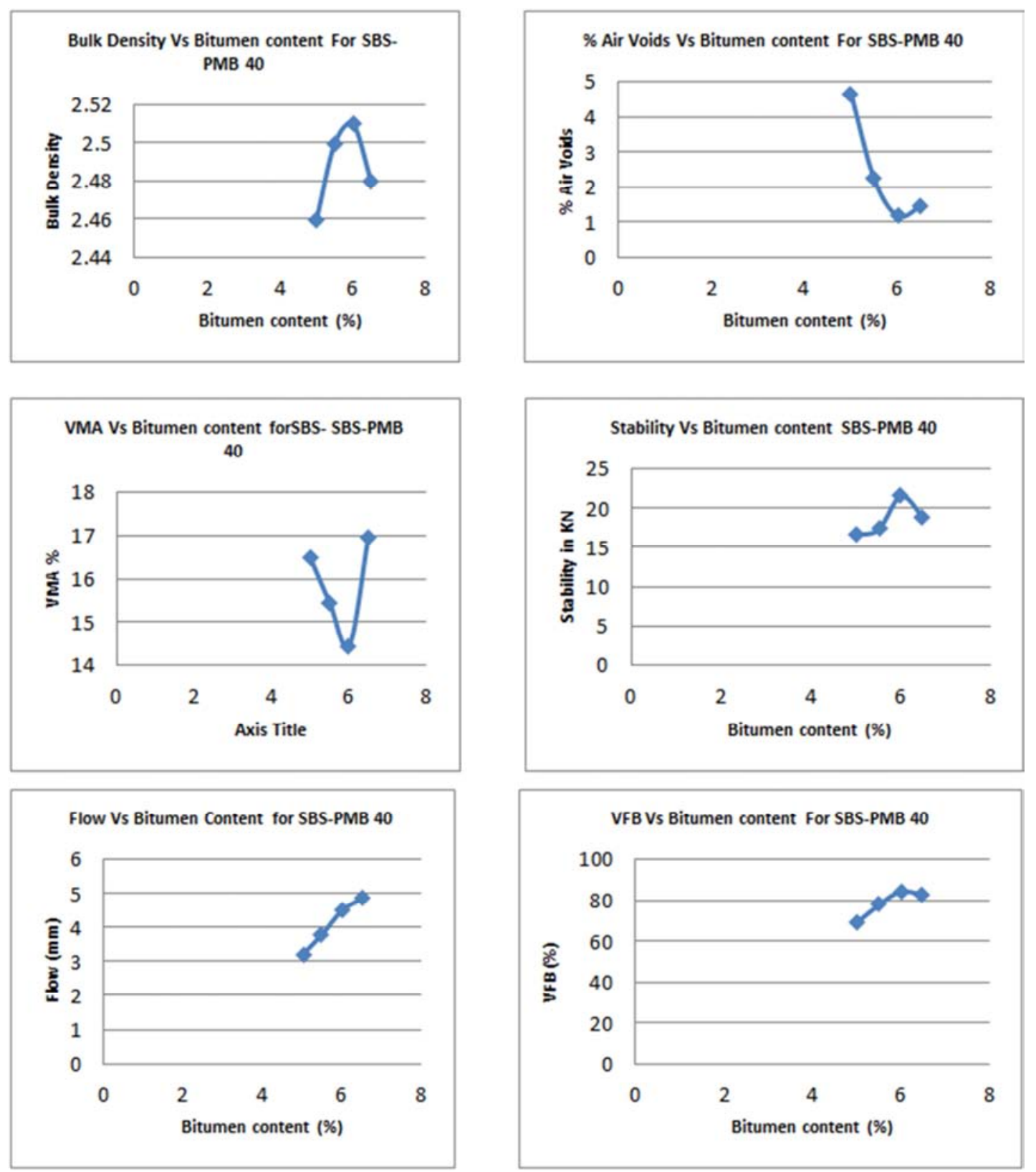

Figure 5. Various Marshall properties of VG-30 and SBS-PMB-40mixes.

Table 10. Stability Test on SBS-PMB 40 Grade Bitumen.

\begin{tabular}{|c|c|c|c|c|c|c|c|}
\hline $\begin{array}{l}\text { SI. No } \\
\end{array}$ & Bitumen Content & Mean Height & Flow dial reading & Flow value (mm) & Proving ring reading & Correction factor & Corrected stability (kn) \\
\hline \multirow{4}{*}{1.} & $5 \%$ & 6.5 & 320 & 3.2 & 267 & 0.948 & 15.56 \\
\hline & $5 \%$ & 6.625 & 330 & 3.3 & 300 & 0.939 & 17.32 \\
\hline & $5 \%$ & 6.575 & 310 & 3.1 & 320 & 0.962 & 18.93 \\
\hline & & & & 3.2 & & & 17.27 \\
\hline \multirow{4}{*}{2.} & $5.5 \%$ & 6.55 & 380 & 3.8 & 299 & 0.943 & 17.34 \\
\hline & $5.5 \%$ & 6.6 & 370 & 3.7 & 284 & 0.943 & 16.47 \\
\hline & $5.5 \%$ & 6.6 & 390 & 3.9 & 274 & 0.96 & 16.17 \\
\hline & & & & 3.8 & & & 16.66 \\
\hline \multirow{4}{*}{3.} & $6 \%$ & 6.27 & 390 & 3.9 & 330 & 1.00 & 20.29 \\
\hline & $6 \%$ & 6.3 & 470 & 4.7 & 350 & 1.01 & 21.74 \\
\hline & $6 \%$ & 6.5 & 490 & 4.9 & 360 & 1.02 & 22.58 \\
\hline & & & & 4.5 & & & 21.53 \\
\hline \multirow{4}{*}{4.} & $6.5 \%$ & 6.225 & 490 & 4.6 & 304 & 1.00 & 18.696 \\
\hline & $6.5 \%$ & 6.375 & 460 & 4.6 & 310 & 0.96 & 18.302 \\
\hline & $6.5 \%$ & 6.275 & 495 & 4.95 & 340 & 0.939 & 19.634 \\
\hline & & & & 4.85 & & & 18.87 \\
\hline
\end{tabular}


Tensile Strength Ratio

Then TSR is calculated as,

$\mathrm{TSR}=($ soaked/un-soaked $) * 100$

Table 11. Tensile Strength Ratio for 30 Blows for Various Grades of Bitumen.

\begin{tabular}{llllll}
\hline \multirow{2}{*}{ Sl.no } & \multirow{2}{*}{ Grade of bitumen } & \multicolumn{2}{l}{ Average load failure kn } & \multicolumn{2}{l}{ Tensile strength ratio\% } \\
(S2/S1) & $\begin{array}{l}\text { Requirement as per } \\
\text { MoRTH Specification }\end{array}$ \\
\cline { 3 - 4 } & & Unsoaked (S1) & Soaked (S2) & 92.40 & \\
2 & VG-30 & 10.27 & 9.49 & MIN $80 \%$ \\
3 & SBS-PMB-40 & 12.528 & 11.645 & 92.95 & \\
4 & VG-30+0.1\%ZYCOTHERM & 9.662 & 9.085 & 94.02 & \\
\hline
\end{tabular}

\section{Static Indirect Tensile Test}

The static indirect test was carried out to study the behavior of paving mixes at different temperatures. The split tensile strength of bituminous mixes was determined by applying a compressive load to Marshall Specimen along the vertical direction, Plane, through two curved steel strips. 12.5 mm wide with the same onside curvature as that of the Marshall SpecimenA nearly uniform tensile stress is developed normal to the direction of the applied load and along the same vertical plane causing the specimen to fail by splitting along the vertical diameter.

Indirect tensile strength of specimen is calculated

$$
\sigma=2 P /(\pi \mathrm{dt})
$$

$\mathrm{P}=$ Load at failure in ' $\mathrm{KN}$ '

$\mathrm{D}=$ Diameter of specimen in ' $\mathrm{mm}$ ' $\mathrm{t}=$ Thickness of specimen in ' $\mathrm{mm}$ ' The values are presented in Table 11 Calculation of material required

Wt of material required $=$ Volume $*$ Bulk density

Wt of material required $=498.72 * 2.45$

$\mathrm{Wt}$ of material required $=1221.86 \mathrm{gm}$

Wag $=$ Wt of aggregates

Wag $+\{(5.25 / 100) * W a g\}=1221.86 \mathrm{gm}$

$\mathrm{Wag}=\{2.45 *[(\pi / 4) * 10 * 10 * 6.35]\} /[1+(5.25 / 100)]$

Wag $=1160.93 \mathrm{gm}$

$\mathrm{Wt}$ of binder $=(5.25 / 100) * 1160.93 \mathrm{Wt}$ of binder $=60.95 \mathrm{gm}$

Table 12. Static Indirect Tensile Strength Test For VG30, SBS-PMB-40 and PMB-zycotherm Grade Bitumen.

\begin{tabular}{llll}
\hline SI.no & Grade of bitumen & Tempts $^{\circ} \mathbf{C}$ & Avg Indirect tensile strength (Mpa) \\
\hline 1 & VG-30 & 30 & 0.735 \\
& VG-30 & 40 & 0.845 \\
2 & SBS-PMB-40 & 30 & 0.855 \\
& SBS-PMB-40 & 40 & 1.02 \\
3 & VG-30+0.1\%ZYCOTHERM & 30 & 0.78 \\
& VG-30+0.1\%ZYCOTHERM & 40 & 0.88 \\
4 & SBS-PMB-40+0.1\%ZYCOTHERM & 30 & 0.885 \\
& SBS-PMB-40+0.1\%ZYCOTHERM & 40 & 1.12 \\
\hline
\end{tabular}

Table 13. Requirements of mix prepared with SBS-PMB-40 as per IRC-SP-53-2010.

\begin{tabular}{lll}
\hline Sl.no & Properties & Requirements \\
\hline 1 & Marshall stability (75blows@60 ${ }^{\circ} \mathrm{C} . \mathrm{kN}$ minimum & 10 \\
2 & Marshall flow@60 $\mathrm{C}, \mathrm{mm}$ & $3.5-5.0$ \\
3 & Airvoids in mix, $\%$ & $3.0-50$ \\
4 & Marshallquotient, kN/mm & $2.5-5.00$ \\
\hline
\end{tabular}

The various results obtained are as shown in table

Table 14. The various results obtained are as shown in table.

\begin{tabular}{|c|c|c|c|c|c|}
\hline \multirow{2}{*}{ Sl.No } & \multirow{2}{*}{ Parameters } & \multicolumn{3}{|l|}{ Results } & \multirow{2}{*}{ limits } \\
\hline & & VG 30 & SBS-PMB - 40 & SBS-PMB - 40+0.1\%zycotherm & \\
\hline 1. & $\mathrm{OBC} \%$ & 5.75 & 5.70 & 5.70 & ------- \\
\hline 2. & Stability $(\mathrm{KN})$ & 13 & 18.8 & 19.2 & Min 9 \\
\hline 3. & Flow (mm) & 3.40 & 4 & 4 & $4-5$ \\
\hline 4. & Unit Weight (gm/cc) & 2.507 & 2.505 & 2.50 & \\
\hline 5. & Percentage Air Voids (Vv\%) & 3 & 1.8 & 1.6 & $3-5$ \\
\hline 6. & VMA $\%$ & 15.6 & 15.2 & 13.5 & $12-15$ \\
\hline 8. & Tensile strength ratio (\%) & 94.02 & 93.82 & 95.47 & $80 \mathrm{~min}$ \\
\hline \multirow[t]{3}{*}{9.} & Static indirect tensile test & & & & \\
\hline & $30^{\circ} \mathrm{C}$ & 0.78 & 0.855 & 0.885 & \\
\hline & $40^{\circ} \mathrm{C}$ & 0.88 & 1.10 & 1.12 & \\
\hline
\end{tabular}




\section{Evaluation of Sasobit Aswarm Mix Asphalt Additive Sasobit}

Sasobit is long chain aliphatic hydrocarbon obtained from coal gasification. After crystallization, Sasobit forms a lattice structure in the binder, which is the basis of the structural stability of the binder containing Sasobit.

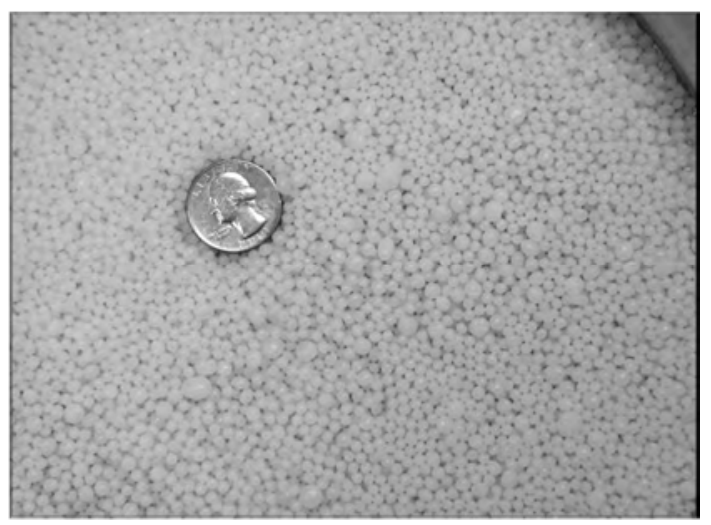

Figure 6. Sasobit prills.

The melting point range of SASOBIT is between $85^{\circ} \mathrm{C}$ $115^{\circ} \mathrm{C}$. Sasobit is completely soluble in bitumen at temperatures in excess of $115^{\circ} \mathrm{C}$. It forms a homogeneous solution with base bitumen on stirring and produces a marked reduction in the bitumen's viscosity. This enables mixing and handling temperatures of the asphalt to be reduced by $10^{\circ} \mathrm{C}-$ $30^{\circ} \mathrm{C}$. Temperature reductions of up to $50^{\circ} \mathrm{C}$ can be reached by process optimization between the mixing plant and paving This in turn results in a significant reduction of bitumen fumes emissions and $\mathrm{CO}_{2}$ (=energy savings) during such operations. During cooling the Sasobit crystallizes out and forms lattice structure in the bitumen which increases the asphalt stability.

The benefits of using Sasobit in WMA are numerous and include:

a. Lower plant mixing temperatures, from $300^{\circ} \mathrm{F}$ to $250^{\circ} \mathrm{F}$, allows for up to a $19 \%$ fuel cost savings to the contractor.

b. Lower mixing temperatures at the plant leads to a reduction in emissions which in turn leads to a reduction in overhead costs related to emissions control.

c. Lower mixing temperatures will minimize oxidative hardening of the asphalt and this will lead to reduced thermal cracking of the pavement and potentially a longer lifetime.

d. When produced at normal temperatures longer haul distances, as well as a longer construction season become possible.

e. Lower emissions during the paving operation provide a healthier work environment for the contractors and the neighborhood in case of a residential project.

f. Sasobit is versatile, safe and is easily blended into the binder at the terminal or into the mix at the Hot Mix Plant.

Sasobit Prills

Optimum bitumen content: $5.75 \%$ for control mix and 5.70\% for SBS-PMB-40 sasobit modified binder (SMB),

Table 15. Optimum bitumen content (SBS-PMB-40 OBC\% and Sasobit binder).

\begin{tabular}{lll}
\hline Control mix OBC\% & SBS-PMB-40 OBC\% & Sasobit binder\%(SMB), \\
\hline 5.75 & 5.70 & $1 \%(0.057 \%$ of 5.70$)$ \\
5.75 & 5.70 & $2 \%(0.114 \%$ of 5.70$)$ \\
5.75 & 5.70 & $3 \%(0.174 \%$ of 5.70$)$ \\
5.75 & 5.70 & $4 \%(0.228 \%$ of 5.70$)$ \\
5.75 & 5.70 & $5 \%(0.285 \%$ of 5.70$)$ \\
5.75 & 5.70 & $6 \%(0.322 \%$ of 5.70$)$ \\
\hline
\end{tabular}

Preparation of Marshall Specimens

Appropriate quantities of mineral aggregates comprising of course aggregates, fine aggregates and mineral fillers such as stone dust were mixed according to gradation selected (tab). the mineral aggregates and binder were heated separetly. Aggregates were heated to temperature of about $10^{\circ} \mathrm{C}$ higher than the corresponding mixing temperature of binder. Required quantity of binder was added to the aggregates and mixing was done at a mixing temperature till aggregates were coated uniformly. Marshall Mould, base plate, and compaction hammer were heated to compaction temperatures before the mix was placed in the mould. Care was being taken to avoid segregation of the mix placed in the mould. The mix was prodded 20times with heated spatula around the perimeter and 10 times on the rest of surface leaving slightly convex surface. The heated hammer was placed in position and mix was compacted by application of number of blows required for compaction method adopted. After the specimens were cooled to room temperature, they were extracted from the moulds.

Five specimens for mixing temperature of $120^{\circ} \mathrm{C}$ with different percentage ofsasobit mixed with binder (SMB) were prepared.

Table 16. Volumetric Properties with Optimum Dosage ofVG-30with\% of Sasobitand Mixing Temperature of $120^{\circ} \mathrm{C}$.

\begin{tabular}{|c|c|c|c|c|c|}
\hline Parameters & $\begin{array}{l}\text { OBC OF VG- } \\
30+4 \% \text { SASOBIT }\end{array}$ & $\begin{array}{l}\text { OBC OF VG- } \\
30+3 \% \text { SASOBIT }\end{array}$ & $\begin{array}{l}\text { OBC OF VG- } \\
30+2 \% \text { SASOBIT }\end{array}$ & $\begin{array}{l}\text { OBC OF VG- } \\
30+1 \% \text { SASOBIT }\end{array}$ & LIMITS \\
\hline Bulk density $\mathrm{g} / \mathrm{cm}^{3}$ & 2.46 & 2.52 & 2.45 & 2.41 & \\
\hline Air voids $\%$ & 2.31 & 2.47 & 2.37 & 3.86 & $3-5$ \\
\hline VMA\% & 11.67 & 11.83 & 12.22 & 13.36 & 12.15 \\
\hline VFB $\%$ & 79.03 & 67.8 & 77.49 & 72.19 & $65-75$ \\
\hline Stability, kn & 15.36 & 15.91 & 16.02 & 12.51 & Min 9 \\
\hline Flow value (mm) & 3.94 & 3.56 & 3.47 & 3.53 & $2-4$ \\
\hline
\end{tabular}

Volumetric Properties with Optimum Dosage of SBS-PMB-40 with\% Sasobitand Mixing Temperature of $120^{\circ} \mathrm{C}$ 
Table 17. Volumetric Properties with Optimum Dosage of SBS-PMB-40 with\% Sasobitand Mixing Temperature of $120^{\circ} \mathrm{C}$.

\begin{tabular}{|c|c|c|c|c|c|}
\hline Parameters & $\begin{array}{l}\text { SBS-PMB- } \\
40+4 \% \text { SASOBIT }\end{array}$ & $\begin{array}{l}\text { SBS-PMB- } \\
40+3 \% \text { SASOBIT }\end{array}$ & $\begin{array}{l}\text { SBS-PMB-40- } \\
+2 \% \text { SASOBIT }\end{array}$ & $\begin{array}{l}\text { SBS-PMB- } \\
40+1 \% \text { SASOBIT }\end{array}$ & LIMITS \\
\hline Bulk density $\mathrm{g} / \mathrm{cm}^{3}$ & 2.46 & 2.42 & 2.45 & 2.41 & \\
\hline Air voids $\%$ & 2.88 & 5.0 & 4.07 & 5.15 & $3-5$ \\
\hline VMA\% & 16.92 & 18.50 & 17.24 & 18.18 & 12.15 \\
\hline VFB $\%$ & 80.88 & 72.16 & 77.82 & 71.21 & $65-75$ \\
\hline Stability, kn & 15.95 & 16.30 & 16.42 & 14.26 & $\operatorname{Min} 9$ \\
\hline Flow value $(\mathrm{mm})$ & 3.95 & 3.42 & 3.25 & 3.18 & $2-4$ \\
\hline
\end{tabular}

Table 18. Comparison of ResultsforSasobitat Mixing Temperature of $120^{\circ} \mathrm{C}$.

\begin{tabular}{llllll}
\hline Parameters & VG-30 & VG+3\%SASOBIT & SBS-PMB-40 & SBS-PMB-40+3\%SASOBIT & LIMITS \\
\hline Bulk density g/cm ${ }^{3}$ & 2.40 & 2.50 & 2.47 & 2.50 & $3-9$ \\
Air voids\% & 2.72 & 4.21 & 1.8 & 1.96 & 15.78 \\
VMA\% & 15.88 & 16.23 & 15.20 & 75.75 & 12.15 \\
VFB\% & 82.27 & 77.27 & 75.0 & 16.31 & $65-75$ \\
Stability, kn & 11.66 & 15.91 & 15.9 & 3.8 & Min 9 \\
Flow value (mm) & 3.0 & 3.56 & 3.56 & 97.9 & $2-4$ \\
Tensile strength ratio & 92.40 & 94.02 & 92.95 & 1.80 & MIN $80 \%$ \\
Average Static Indirect Tensile Strength & 0.75 & 0.80 & 0.84 & \\
\hline
\end{tabular}

\section{Evaluation of Evotherm as Warm Mix Asphalt Additive} EVOTHERM

EVOTHERMis an innovative warm mix asphalt technology that includes additives to improve coating, surfactants to enhance aggregate-binder adhesion, and agents to promote workability and compaction. EVOTHERM M1 can be added at the asphalt terminal or at the mix plant and is useful for producing warm mix asphalt based on all common formulation ingredients, including modified and unmodified asphalt binders, asphalt rubber, silicate and calcareous aggregates, and RAP materials. EVOTHERM M1 warm mixes can be used for all pavement layers and are ideal for dense-graded mixes, SMA mixes, OGFC mixes, polymer modified asphalts, ultra-thin overlays, and asphalt rubber mixes. EVOTHERM M1 can be used with a wide variety of asphalts and does not adversely impact the asphalt binder performance grade, including asphalt binders modified with SBS, SBR, or EVA.

The use of EVOTHERM M1 allows mix producers and pavement contractors to realize temperature reductions of 35 to $50^{\circ} \mathrm{C}\left(63\right.$ to $\left.90^{\circ} \mathrm{F}\right)$ compared to conventional HMA. Lower temperatures mean less fuel consumption, lower stack emissions, and less fume and odor generation at the plant and job site. Lower temperatures also mean less binder oxidation, which should result in greater crack resistance and longer pavement service life. Mixes based on EVOTHERM chemistry meet Marshall and SHRP volumetric design specifications. Additionally, EVOTHERM warm mixes handle like hot mix and give in-place performance properties meeting or exceeding hot mix asphalt pavement specifications.

EVOTHERM chemistries are tailored to meet the widely varying demands of warm mix asphalt mixture production and paving operations. EVOTHERM M1 meets or exceeds the minimum amine value requirements for use as an adhesion promoter set by many state DOTs.

Evotherm is a new generation chemical additive developed in the USA by MeadWestvaco Asphalt Innovations, Charleston, South Carolina (now Ingevity Inc.). It is based on a chemical process that can be delivered in the form of high residue asphalt emulsion. Water in the form of steam is releasedwhen the Evotherm is mixed with hot aggregate. Evotherm can also be delivered as a water based soap solution known as Evotherm DAT, or as a chemical package that does not contain water known as Evotherm-3G. The chemistry that led to the successful production of the Evotherm has the potential to improve coating, workability, and adhesion in asphalts. The Evotherm technology can also be modified and delivered in three different forms as described below. 1) Evotherm ET (Emulsion Technology) (First Generation) - a high asphalt cement (AC) content, water-based asphalt emulsion. Evotherm ET requires no plant modifications. 2) Evotherm DAT (Dispersed Asphalt Technology) (Second Generation) - a concentrated solution of Evotherm additives in-line injected at the mix plant. Evotherm DAT allows for flexibility. 3) Evotherm 3G (Third Generation)-This was developed in partnership with Paragon Technical Services and Mathy Technology \& Engineering. This category of Evotherm, which is an Evotherm, $3 \mathrm{G}$ is in water-free form.

Table 19. Physical and Chemical Properties of Evotherm.

\begin{tabular}{lll}
\hline Sl.no & Description & Properties \\
\hline 1 & Product Identifier & EVOTHERM-3G \\
2 & Chemical Name & Fatty-amine derivative \\
3 & Physical State & Liquid \\
4 & Colour & Amber (Dark) \\
5 & Odour & Amine-like \\
6 & Melting Point & $\left.<-22^{\circ} \mathrm{F}\right)$ \\
7 & PH Value & 10 to $12($ Conc. $(\% \mathrm{w} / \mathrm{w}): 15 \%)$ \\
8 & Boiling Point & $>200^{\circ} \mathrm{C}\left(>392^{\circ} \mathrm{F}\right)$ \\
9 & Flash point Closed cup & $>266^{\circ} \mathrm{C}\left(>510^{\circ} \mathrm{F}\right)$ \\
10 & Relative Density & $0.97($ Water $=1)$ \\
11 & Solubility & Partially soluble in Hot and Cold \\
12 & Auto-ignition Temperature & water \\
13 & Flammability & NA \\
\hline
\end{tabular}


Table 20. Optimum bitumen content: $5.75 \%$ for control mix and 5.70\% for SBS-PMB-40 Evotherm modified binder (EMB).

\begin{tabular}{llll}
\hline Control mix OBC $\%$ & SBS-PMB-40 OBC\% & VG30+\% of Evotherm & VG30+\% of Evotherm \\
\hline 5.75 & 5.70 & $0.2 \%$ of 5.75 & $0.2 \%$ of 5.70 \\
5.75 & 5.70 & $0.4 \%$ of 5.75 & $0.4 \%$ of 5.70 \\
5.75 & 5.70 & $0.5 \%$ of 5.75 & $0.5 \%$ of 5.70 \\
5.75 & 5.70 & $0.6 \%$ of 5.75 & $0.6 \%$ of 5.70 \\
\hline
\end{tabular}

\section{Preparation of Marshall Specimens}

Appropriate quantities of mineral aggregates comprising of course aggregates, fine aggregates and mineral fillers such as stone dust were mixed according to gradation selected (tab). the mineral aggregates and binder were heated separetly. Aggregates were heated to temperature of about $10^{\circ} \mathrm{C}$ higher than the corresponding mixing temperature of binder. Required quantity of binder was added to the aggregates and mixing was done at a mixing temperature till aggregates were coated uniformly. Marshall Mould, base plate, and compaction hammer were heated to compaction temperatures before the mix was placed in the mould. Care was being taken to avoid segregation of the mix placed in the mould. The mix was prodded 20times with heated spatula around the perimeter and 10 times on the rest of surface leaving slightly convex surface. The heated hammer was placed in position and mix was compacted by application of number of blows required for compaction method adopted. After the specimens were cooled to room temperature, they were extracted from the moulds.

Five specimens for mixing temperature of $120^{\circ} \mathrm{C}$ with different percentage ofEvotherm mixed with binder (EMB) were prepared.

Table 21. Volumetric Properties with Optimum Dosage ofVG-30with\% of Evothermand Mixing Temperature of $120^{\circ} \mathrm{C}$.

\begin{tabular}{lllll}
\hline Parameters & OBC OF VG-30+ 0.2\% Evotherm & OBC OF VG-30+0.4\% Evotherm & OBC OF VG-30+.0.6\% Evotherm & LIMITS \\
\hline Bulk density $\mathrm{g} / \mathrm{cm}^{3}$ & 2.56 & 2.53 & 2.51 & \\
Air voids\% & 4.41 & 5.92 & 2.71 & $3-5$ \\
VMA\% & 13.36 & 16.51 & 15.31 & 12.15 \\
VFB\% & 64.98 & 61.90 & 82.29 & $65-75$ \\
Stability, kn & 11.83 & 11.35 & 11.77 & Min 9 \\
Flow value (mm) & 3.00 & 3.20 & 3.40 & $2-4$ \\
\hline
\end{tabular}

Table 22. Volumetric Properties with Optimum Dosage of SBS-PMB-40 with\% Sasobitand Mixing Temperature of $120^{\circ} \mathrm{C}$.

\begin{tabular}{lllll}
\hline Parameters & SBS-PMB-40 +0.2\% Evotherm & SBS-PMB-40 +0.4\% Evotherm & SBS-PMB-40 -+0.6\% Evotherm & LIMITS \\
\hline Bulk density g/cm $\mathbf{c m}^{3}$ & 2.47 & 2.42 & 2.51 & $3-5$ \\
Air voids\% & 2.79 & 3.62 & 2.71 & 16.35 \\
VMA\% & 15.25 & 16.51 & 82.29 & $65-75$ \\
VFB\% & 61.90 & 84.98 & 11.77 & Min 9 \\
Stability, kn & 15.8 & 11.35 & 3.4 & $2-4$ \\
Flow value (mm) & 3.60 & 3.2 & & \\
\hline
\end{tabular}

Table 23. Comparison of ResultsforEvotherm at Mixing Temperature of $120^{\circ} \mathrm{C}$.

\begin{tabular}{|c|c|c|c|c|c|}
\hline Parameters & VG-30 & SBS-PMB-40 & $\begin{array}{l}\text { OBC OF VG-30+ } 0.2 \% \\
\text { Evotherm }\end{array}$ & $\begin{array}{l}\text { SBS-PMB-40 +0.2\% } \\
\text { Evotherm }\end{array}$ & LIMITS \\
\hline Bulk density $\mathrm{g} / \mathrm{cm}^{3}$ & 2.40 & 2.47 & 2.56 & 2.47 & \\
\hline Air voids $\%$ & 2.72 & 1.8 & 4.41 & 2.79 & $3-5$ \\
\hline VMA $\%$ & 15.88 & 15.20 & 13.36 & 15.25 & 12.15 \\
\hline VFB $\%$ & 82.27 & 75.0 & 64.98 & 61.90 & $65-75$ \\
\hline Stability, kn & 11.66 & 15.9 & 11.83 & 15.8 & $\operatorname{Min} 9$ \\
\hline Flow value $(\mathrm{mm})$ & 3.0 & 3.56 & 3.00 & 3.60 & $2-4$ \\
\hline Tensile strength ratio & 92.40 & 92.95 & 95.50 & 95.94 & MIN $80 \%$ \\
\hline Average Static Indirect Tensile Strength & 0.75 & 0.84 & 0.95 & 0.98 & \\
\hline
\end{tabular}

Table 24. Comparisons of VG30, SBS-PMB-40, SASOBIT (SMB), and EVOTHERM (EMB) Mixes at a Mixing Temperature of $120^{\circ} \mathrm{C}$.

\begin{tabular}{|c|c|c|c|c|c|c|c|}
\hline Parameters & $\begin{array}{l}\text { VG- } \\
30\end{array}$ & $\begin{array}{l}\text { SBS-PMB- } \\
40\end{array}$ & $\begin{array}{l}\text { VG-30+ 0.2\% } \\
\text { Evotherm }\end{array}$ & $\begin{array}{l}\text { SBS-PMB-40 } \\
+0.2 \% \text { Evotherm }\end{array}$ & VG+3\%SASOBIT & $\begin{array}{l}\text { SBS-PMB-40 } \\
+3 \% \text { SASOBIT }\end{array}$ & LIMITS \\
\hline Bulk density $\mathrm{g} / \mathrm{cm}^{3}$ & 2.40 & 2.47 & 2.56 & 2.47 & 2.50 & 2.50 & \\
\hline Air voids \% & 2.72 & 1.8 & 4.41 & 2.79 & 4.21 & 1.96 & $3-5$ \\
\hline VMA $\%$ & 15.88 & 15.20 & 13.36 & 15.25 & 16.23 & 15.78 & 12.15 \\
\hline VFB $\%$ & 82.27 & 75.0 & 64.98 & 61.90 & 77.27 & 75.75 & $65-75$ \\
\hline Stability, kn & 11.66 & 15.9 & 11.83 & 15.8 & 15.91 & 16.31 & $\operatorname{Min} 9$ \\
\hline Flow value (mm) & 3.0 & 3.56 & 3.00 & 3.60 & 3.56 & 3.8 & $2-4$ \\
\hline Average Static Indirect Tensile Strength & 0.75 & 0.84 & 0.95 & 0.98 & 0.80 & 1.80 & \\
\hline
\end{tabular}




\section{Conclusions}

a. The temperature required for mixing and compaction of bitumen with WMA (warm mix asphalt) chemicals is reduced as compared to the bitumen without WMA about $40^{\circ} \mathrm{C}$

b. Optimum binder content is determined as $5.75 \%$ for VG-30, and $5.70 \%$ for SBS-PMB-40 of Marshall mix design.

c. Optimum amount of dosage forSasobit was found to be $2 \%$ by weight of bitumen.

d. Optimum amount of dosage forEvothermt was found to be $0.2 \%$ by weight of bitumen.

e. The mixing and compaction temperatures was reduces by $30^{\circ} \mathrm{C}$ with Sasobit modified bitumen (SBS-PMB-40 with Sasobit)

f. The mixing and compaction temperatures was reduces by $40^{\circ} \mathrm{C}$ with evotherm modified bitumen (SBS-PMB40 with Evotherm)

g. The tensile strength ratio of SBS-PMB-4O grade bitumen is greater than that of VG30grade bitumen

h. The tensile strength ratio of SBS-PMB-4O with 3\% sasobitis greater than that of

i. SBS-PMB-4O and VG-30 grade bitumen

j. The tensile strength ratio of SBS-PMB- $4 \mathrm{O}$ with $0.2 \%$ Evothermis greater than that of

k. SBS-PMB-4O and VG-30 grade bitumen

1. Stability and density of mix improved with addition of $3 \%$ sasobit in VG-30 and SBS-PMB-40

m.Flow, Voids Filled with Bitumen (VFB) of Warmmix asphalt increased with increase in temperature at Optimum content of 3\%Sasobit and $0.2 \%$ Evotherm

n. Air Voids and Voids in mineral aggregates (VMA) of WMA with Sasobit and evotherm decreased as compared to VG-30 mix.

o. Static indirect tensile strength of VG30 grade bitumen is lesser than that of SBS-PMB-4O grade bitumen

p. Static indirect tensile strength of $\mathrm{VG} 30+3 \%$ sasobitgrade bitumen is lesser than that of VG30grade bitumen

q. Static indirect tensile strength of SBS-PMB-40 $+3 \%$ sasobitgrade bitumen is lesser than that of VG30grade bitumen

r. Fuel consumption for heating the bitumen with WMA is reduced as compared to without WMA chemical

\section{References}

[1] Adedeji, A., Grunfelder, T., Bates, F. S., Macosko, C. W., Stroup-Gardiner, M., Newcomb, D. E. (1996). "Asphalt Modified by SBS Triblock Copolymer Structure and Properties.” Polymer Engineering and Science, 36 (12), $707-$ 1723.

[2] Akisetty, C. K. K. (2008). "Evaluation of Warm Mix Asphalt Additives on Performance Properties of CRM Binders and Mixtures" Dissertation, Department of Civil Engineering, Clemson University.
[3] Al-Abdul Wahhab, H. I., Asi, I. M., Ali, F. M., and Al-Dubabi, I. A. (1999). "Prediction of Asphalt Rheological Properties Using HP-GPC." Journal of Materials in Civil Engineering, ASCE, 11 (1), 6-14.

[4] Al-Rawashdeh, A. (2008). "Performance Assessment of Warm Mix Asphalt (WMA) Pavements.” Thesis, The Russ College of Engineering and Technology, Ohio Univeristy.

[5] Anderson, R. M., Baumgardner, G., May, R., and Reinke, G. (2008). "Engineering Properties, Emission, and Field Performance of Warm Mix Asphalt Technologies." Asphalt Institute, NCHRP 9-47.

[6] Asphalt Institute. (2003). "Performance Graded Asphalt Binder Specification and Testing." SHRP Series No. 1 (SP-1). Astec Inc. Website: http://www.astecinc.com/

[7] Airey, G. D., State of the Art Report on Ageing Test Methods for Bituminous Pavement Materials, International Journal of Pavement Engineering, Vol. 4, No. 3, 2003, pp. 165-176.

[8] Arafatyero, S., and Hainin, M. R., The Influence of ShortTerm Agingon Bitumen Properties, ARPN Journal of Science and Technology, Vol. 2, No. 7, 2012, pp. 597-599.

[9] Australia, 2012, pp. 1-13 Singh, M., Kumar, P., Maurya, M. R. and Gupta, M., Aging Effect on Modified Bitumen.

[10] Andrew Thomas LaCroix "Performance Prediction of the NCAT Test Track Pavements Using Mechanistic Models" Raleigh, North Carolina 2012.

[11] Awanti, S. S., Amarnath, M. S., and Veeraragavan, A. (2008). "Laboratory evaluation 311 of SBS modified bituminous paving mix." Journal of Materials in Civil Engineering, 20 (4), 327-330.

[12] Awanti, S. S., Amarnath, M. S. \& Veeraragavan A. (2007). "Influence of rest periods on fatigue characteristics of SBS polymer modified bituminous concrete mixtures." Int J Pavement Eng., 8, 177-186.

[13] Azari, H., McCuen, R. H., and Stuart, K. D. (2003). Optimum compaction temperature for modified binders, Journal of Transportation Engineering, 129, pp. 531-537.

[14] Becker, Y., Mendez, M. P., and Rodriguez, Y. (2001). "Polymer Modified Asphalt." Vis Technol, 9 (1). 39-50.

[15] Biro, S. (2005). "Chemically Stabilized Asphalt Rubber." Dissertation, Department of Hydrocarbon and Coal Processing, University of Veszprem, Hungary.

[16] Blanchard, C. R. (1996). "Atomic Force Microscopy." The Chemical Educator, 1 (5), 1-8.

[17] Boggs, D. (2008). "Warm Mix Demo, Rock Hill, South Carolina." NAPA's 53th Annual Meeting.

[18] Brown, D. C. (2008). "Warm Mix: the Light sare Green." Hot Mix Asphalt Technology, January/February, 20-22.

[19] Brundage, B. (2008). "Photoshop Elements 6: The Missing Manual.” O'Reilly Media, Inc., ISBN-13: 978-0-596-51444-0, 189-191. 157.

[20] Budija, M., Cornelius, P., Johnson, S., Parry, M., and Webb, C. (2004). "The Development of High Performance Polymer Modified Binders for Asphalt Use with Improved Fuming Characteristics.” BP Australia Limited. 
[21] Button, J. W., Estakhri, C., and Wimsatt, A. (2007). "A Synthesis of Warm-Mix Asphalt." Texas Transportation Institute, Report No. TX-07/0-5597-1.

[22] Caro, S., Masad, E., Bhasin, A, and Little, D. N. (2008). "Moisture Susceptibility of Asphalt Mixture, Part 1: Mechanisms." International Journal of Pavement Engineering, 9 (2), 81-98.

[23] Carter, M. J. (2008). "Warm Mix Asphalt" Technical Brief, Delaware T2 enterasola, J. (2006). "Modified Asphalt Market 2005-2006." The Association of Modified Asphalt Producers Meeting.

[24] Chadbourn, B. A., Skok, E. L., Newcomb, D., Crow, B. L., and Spindler, S. (2000). "The Effect of Voids in Mineral Aggregate (VMA) on Hot Mix Asphalt Pavements." Minnesota Department of Transportation, Report No. MN/RC2000-13.

[25] Chen, J. S., Liao, M. C, and Tsai, H. H. (2002). "Evaluation of Optimization of the Engineering Properties of PolymerModified Asphalt.” Practical Failure Analysis, 2 (3), 75-83.

[26] Chen, J. S., Liao, M. C., and Shiah, M. S. (2002). “Asphalt Modified by Styrene- Butadiene-Styrene Triblock Copolymer: Morphology and Model." Journal of Materials in Civil Engineering, ASCE, 224-225.

[27] Chowdhury, A., and Button, J. W. (2008). "A Review of Warm Mix Asphalt." Texas Transportation Institutet, Report No. SWUTC/08/473700-00080-1.

[28] Cliff, U. (2008). "Ohio Warm Mix Asphalt DemoPreliminary Results.” NAPA's53th Annual Meeting.

[29] Colorado DOT. (2008). "Warm Mix for a ColdClimate." ColoradoTransportation Conference.

[30] Copeland, A. R., Youtcheff, J., and Shenoy, A. (2007). "Moisture Sensitivity of Modified Asphalt Binders." Transportation Research Board, 86th Annual Meeting, Washington DC, 18-28.

[31] Corrigan, M. (2006). "Warm Mix Asphalt Technologies and Research" Federal Highway Administration, Website: http//www.fhwa.dot.gov/pavement. 158.

[32] Croteau, J. M., and Tessier, B. (2008). "Warm Mix Asphalt Paving Technologies: a Road Builder's Perspective" Annual Conference of the Transportation Association of Canada, 2-11.

[33] Collins, J. H., Bouldin, M. G., Gelles, R., and Berker, A. (1991). "Improved performance of paving asphalts by polymer modification." J. Assoc. of Asphalt Paving Technologists, 60, 43-79.

[34] D’Angelo, J., Harm, E., Bartoszek, J., Baumgardner, G., Corrigan, M., Cowsert, J., Harman, T., Jamshidi, M., Jones, W., Newcomb, D., Prowell, B., Sines, R., and Yeaton, B. (2008). "Warm-Mix Asphalt: European Practice, International Technology Scanning Program.” Federal Highway Administration, FHWA-PL-08-007.

[35] Dehouche, N., Kaci, M., and Mokhtar, K. A., Influence of Thermo-Oxidative Aging on Chemical Composition and Physical Properties of Polymer Modified Bitumens, Construction and Building Materials, Vol. 26, 2012, pp. 350-356.

[36] Daragna, C. (1999). "Characterization of Aged Polymer Modified Asphalt Cements for Recycling Purposes."
Dissertation, Agricultural and Mechanical College, Louisiana State University.

[37] Dessouky, S., Reyes, C., Ilias, M., Contreras, D. and Papagiannakis, A. T., Effect of Pre-heating Duration and Temperature Conditioning on the Rheological Properties of Bitumen, Construction and Building Materials, Vol. 25, 2011, pp. 2785-2792.

[38] Durrieu, F., Farcas, F. and Mouillet, V., The Influence of UVA gingofa Styrene/Butadiene/Styrene Modified Bitumen: Comparison between Laboratory and On Site Aging, Fuel, Vol. 86, 2007, pp. 1446-1451.

[39] Edwards, Y., and Redelius, P. (2003). "Rheological Effects of Waxes in Bitumen." Energy and Fuels, An American Chemical Society Journal.

[40] Edwards, Y., Tasdemir, Y., and Isacsson, U. (2006). "Rheological Effects of Commercial Waxes and Phosporic Acid in Bitumen 160/22 - Low Temperature Performance." Fuel 85, 989-997.

[41] EPA Website: http://www.epa.gov/Eurovia Services Website: http://www.eurovia.com.

[42] Fillers of Different Origin, Foundations of Civil and Environmental Engineering, Vol. 10, pp. 39-49. 9. Peterson, J. C., A Review of the Fundamentals of Asphalt Oxidation, Transportation Research Board, 2009, 500 fifth Street, NW, Washington DC 20001.

[43] Fernández-Gómez, W. D., Quintana, H. R. and Lizcano, F. R., A review of asphalt andasphalt mixture aging, Ingeniería $\mathrm{E}$ Investigación, Vol. 33, No. 1, 2013, pp. 5-12.

[44] Gandhi, T. (2008). "Effects of Warm Asphalt Additives on Asphalt Binder and Mixture Properties" Dissertation, Department of Civil Engineering, Clemson University.

[45] Gelman, A. (2004). "Analysis of Variance - Why it is more important than ever." Special Invited lecture for the Institute of Mathematical Statistics, 1-9.

[46] Goh, S. W., and You, Z. (2008). "Warm Mix Asphalt using Sasobit ${ }^{\circledR}$ : Field and Laboratory Experience." Proceedings of the 2008 Mid-Continent Transportation Research Forum, Madison, Wisconsin.

[47] Grabowski, W., Wilanowicz, J., Słowik, M., and Soból, T., Research into the Influence of Short-Term Ageing on the Change in the Rheological Properties of Mastics Containing.

[48] Guern, M. L., Chailleux, E., Farcas, F., Dreessen, S. and Mabille, I., Physico-Chemical Analysis of Five Hard Bitumens: Identification of Chemical Speciesand Molecular Organization Before and After Artificial Aging, Fuel, Vol. 89, 2010, pp. 3330-3339.

[49] Hefer, A., and Little, D. (2005). "Adhesion in BitumenAggregate System and Quantification of the Effects of Water on the Adhesive Bond." Texas Transportation Institute, Report No. ICAR/505-1.

[50] Hakseokim et al 2010.

[51] Huang, S. C., Robertson, R. E., Branthaver, J. F., and Peterson, J. C. (2005). "Impact of Lime Modification of Asphalt and FreezeThaw Cycling on the Asphalt-Aggregate interaction and Moisture Resistance to Moisture Damage." Journal of Materials in Civil Engineering, ASCE, 17 (6), 711-717. 159. 
[52] Hesp, S. A. M., Iliuta, S and Shirokoff, J. W., Reversible Ageing in Asphalt Binders, Energy Fuels, Vol. 21, 2007, pp. 1112-1121.

[53] Hurley, G. C., and Prowell, B. D. (2005). "Evaluation of Aspha-Min ${ }^{\circledR}$ Zeolite for Use in Warm Mix Asphalt.” National Center for Asphalt Technology, Report 05-04 (a).

[54] Hurley, G. C., and Prowell, B. D. (2005). "Evaluation of Sasobit ${ }^{\circledR}$ for Use in Warm Mix Asphalt.” National Center for Asphalt Technology, Report 05-06 (b).

[55] Hensley, J. and Palmer, A., 1998. Establishing.... Effects of non-foaming WMA additives on asphalt binders at high performance temperatures.

[56] Hurley, G. C., and Prowell, B. D. (2006). "Evaluation of Evotherm ${ }^{\circledR}$ for Use in Warm Mix Asphalt." National Center for Asphalt Technology, Report 06-02.

[57] Illinois DOT. (2005). "Pavement Technology Advisory." PTAD5, 1-2.

[58] International Journal of Engineering, Science and Metallurgy, Vol. 2, No. 3, 2012, pp. 727-731.

[59] Illinois DOT. (2005). "Polymer Modified Hot Mix Asphalt." Design, Construction and Materials, Bureau of Materials and Physical Research, PTA-D5.

[60] Iwański, M. and Mazurek, G., Hydrated Lime as the Antiaging Bitumen Agent, in the proceedings of 11th International Conference on Modern Building Materials, Structures and Techniques, MBMST 2013, Procedia Engineering, Vol. 57, pp. 424- 432

[61] Jager, A., Lackner, R., Sittner, Ch. E., and Blab, R. (2004). "Identification of Four Materials Phase in Bitumen by Atomic Force Microscopy." Road Materials and Pavement Design, EATA, 9-24.

[62] Jennings, P. W. (1980). "High Pressure Liquid Chromatography as a Method of Measuring Asphalt Composition.” Publication FHWA-MT-7930, FHWA, U. S. Department of Transportation.

[63] Jennings, P. W. and Prabanic, J. A. S. (1985). “The Expanded Montana Asphalt Quality Study Using High Pressure Liquid Chromatography.” Publication FHWA- MT-85-001, FHWA, U. S. Department of Transportation.

[64] Jones, D., Wu, R., Tsai, B., Lu, Q., and Harvey, J. T. (2008). "Warm-Mix Asphalt Study: Test Track Construction and First level Analysis of Phase 1 HVS and Laboratory Testing." California Department of Transportation, Research Report No. UCPRC-RR-2008-11.

[65] Jones, W. (2004). "Warm Mix Asphalt Pavement" Asphalt, Fall, 8-11.

[66] James, A. D. and Stewart, D., The Use of Fatty Amine Derivatives to Slow Down the Age-Hardening Process in Bitumen, in the proceedings of The Chemistry of Bitumen, 1991, Rome, pp. 671-684.

[67] Kaitkus, A., Cygas, D., Laurinavicius, A., and Perveneckas, Z. (2009). "Analysis and Evaulation of Possibilities for the Use of Warm Mix Asphalt in Lithuania" The Baltic Journal of Road and Bridge Engineering, 4 (2), 80-86.

[68] Kandhal, P. S., and Cooley, L. A. Jr. (2003). “Accelerated Laboratory Rutting Tests: Evaluation of the Asphalt Pavement
Analyzer." National Cooperative Highway Research Program Report 508, Transportation Research Board, National Research Council, Washington, D.C.

[69] Kanitpong, K., Nam, K., Martono, W., and Bahia, H. (2008). "Evaluation of a Warm- Mix Asphalt Additive" Construction Materials, 161 Issue CMI, 1-8. 160

[70] Kim, B. (2003). "Evaluation of the Effect of SBS Polymer Modifier on Cracking Resistance of Superpave Mixtures." Dissertation, University of Florida, 20-23.

[71] Kim, H. S., Lee, S.-J., Amirkhanian, S. (2010). "Effects of Warm Mix Asphalt Additives on Performance Properties of Polymer Modified Asphalt Binders." Canadian Journal of Civil Engineering Vol. 37, No. 1, 17-24.

[72] Kim, K. W., Burati, J. L. and Park, J. S. (1995). "Methodology for Defining LMS Portion in Asphalt Chromatogram.” Journal of Materials in Civil Engineering, ASCE, 7 (1), 31-40.

[73] Kim, K. W., Doh, Y. S. and Amirkhanian, S. N. (2004). "Evaluation of Aging Characteristics of Selected PMA using HP-GPC." Journal of Korean Society of Pavement Engineers, $6(2), 15-24$.

[74] Kim, K. W., Kim, K., Doh, Y. S., and Amirkhanian, S. N. (2006). "Estimation of RAP's binder viscosity using GPC without binder recovery." Journal of Materials in Civil Engineering, ASCE, 18 (4), 227-232.

[75] Kirk, J. V. (2009). "Contractor's Perspective: RHMA Warm Mix Asphalt Project." California Warm Mix Asphalt Conference.

[76] Kitto, A. M., Pirbazari, M., Badriyha, B. N., Ravindran, V., Tyner, R. and Synolakis, C. E. (1997). "Emissions of Volatile and Semi-Volatile Organic Compounds and Particulate Matter from Hot Asphalts" Environmental Technology, 18 (2), 121138.

[77] Khatri, A., Bahia, H. U., and Hanson, D. (2001). Mixing and Compaction Temperatures for Modified Binders using the Superpave Gyratory Compactor, Journal of the Association of Asphalt Paving Technologists, 70, pp. 368-402.

[78] Kliewer, J. E., Bell, C. A., and Sosnovske, D. A. (1995). "Investigation of the relationship between field performance and laboratory aging properties of asphalt mixtures" Proceedings of the symposium on engineering properties of asphalt mixtures and the relationship to their performance, ASTM STP 1265, West Conshohocken, Pa, 3-10.

[79] Koenders, B. G., Stoker, D. A., Bowen, C., Groot, P., Larsen, O., Hardy, D., and Wilms, K. P. (2000). "Innovate Process in Asphalt Production and Application to obtain Lower Operating Temperatures." 2nd Euraphalt \& Eurobitume Congress, Barcelona, Spain, Book II, 830-831.

[80] Int. J. Struct. \& Civil Engg. Res. 2012. Ravi K Sharma et al., 2012Khattak and Baladi (2001) Styrene (SBS) polymer modified binder has. SBS sembleaméliorer les performances de fatigue des bitumes et des enrobés.... Warm Mix Asphalt (WMA) additives (surfactants, zeolite or waxes)...... 1987; Coplantz, Yapp, \& Finn, 1993; Khattak \& Baladi, 2001; Kennedy,...... Page 79.

[81] Kristjánsdóttir, O. (2006). "Warm Mix Asphalt for Cold Weather Paving." Thesis, Department of Civil Engineering, University of Washington, 34-43. 161. 
[82] Kristjánsdóttir, O., Muench, S. T., Michael, L., and Burke, G. (2007). "Assessing Potential for Warm-Mix Asphalt Technology Adoption.” Journal ofthe Transportation Research Board, No. 2040

[83] Kuang, D, Yu, J., Feng, Z., Li, R., Chen, H., Guan, Y., and Zhang, Z., Performance Evaluation and Preventive Measures for Aging of Different Bitumens, Construction and Building Materials, Elsevier, Vol. 66, 2014, pp. 209-213.

[84] Kuehl, R. O. (1999). "Design of Experiments: Statistical Principles of Research Design and Analysis.” Duxbury Press, 2nd edition, ISBN-10: 0534368344.

[85] Kumar and sing et al 2013 Evaluating performance of PPAand-elvaloy-modified binder containing WMA additives and lime using MSCR and LAS tests.

[86] D Singh, PK Ashish, A Kataware... - Journal of Materials in ..., 2017 - ascelibrary.org.

[87] Lavin, P. (2003). “A Practical Guide to Design, Production and Maintenance for Engineers and Architects, CRC Press.

[88] Maintenance for Engineers and Architects.” Taylor \& Francis, 1st Edition, 279-280.

[89] Lee, S. J., Amirkhanian, S. N., and Kim, K. W. (2009). "Laboratory Evaluation of the Effects of Short-term Oven Aging on Asphalt Binders in Asphalt Mixtures using HPGPC." Construction and Building Materials, Vol. 23 (9), pp. 3087-3093.

[90] Li, G., Zhao, Y., and Pang, S. S. (1998). "Microscopic Mechanical Modeling of Polymer Modified Asphalt Composite." Conference Proceedings at ANTEC '98, Atlanta, Georgia, 1720-1721.

[91] Li, Y., and Nazarian, S. (1995). "Evaluation of Aging of Hotmix Asphalt using Wave Propagation Techniques." Engineering properties of asphalt mixtures and the relationship to their performance, ASTM, STP 1265, 167-168.

[92] Loeber, L., Sutton, O., Morel, J., Valeteon, J. M., and Muller, G. (1996). "New Direct Observations of Asphalts and Asphalt Binder by Scanning Electron Microscopy." Journal of Microscopy, Vol. 182, 32-39.

[93] Lamontagne, J., Dumas, P., Mouillet, V. and Kister, J., Comparison by Fourier Trans form Infrared (FTIR) Spectroscopy of Different Ageing Techniques: Applicati onto Road Bitumens, Fuel, Vol. 80, 2001, pp. 483-488.

[94] Lopes, M. M., Zhao, D.; Chailleux, E.; Kane, M.; Gabet, T.; Petiteau, C., Characterization of Aging Processes on the Asphalt Mixture Surface" in the proceedings of 2nd International Symposium on, Asphalt Pavements et Environnement, Transportation Research Board, of The National Academies, 2012, France, pp. 1-10.

[95] Lu, X., and lsacsson, U., Chemical and Rheological Evaluation of Ageing Properties of SBS Polymer Modified Bitumens, Fuel, Vol. 7, 1998, pp. 961-972.

[96] Mallick, R. B., and Bergendahl, J. (2009). “A Laboratory Study on $\mathrm{CO}_{2}$ Emission from Asphalt Binder and Its Reduction with the use of Warm Mix Asphalt." International Journal of Sustainable Engineering, iFirst article, 1-9.

[97] Mallick, R. B., Kandhal, P. S., and Bradbury, R. L. (2008). "Using Warm-Mix Asphalt Technology to Incorporate High
Percentage of Reclaimed Asphalt Pavement Material in Asphalt Mixtures." Journal of the Transportation Research Board, No. 2051.

[98] Masson, J. F., Leblond, V., and Margeson, J. (2006). "Bitumen Morphologies by Phase-Detection Atomic Force Microscophy."Journal of Microscopy, Vol. 221, 17-29.

[99] Mastrofini, D. and Scarsella, M., The Application of Rheology to the Evaluation of Bitumen Ageing, Fuel, Vol. 79, 1999, pp. 1005-1015.

[100] Mouillet, V., Farcas, F. and Besson, S., Ageing by UV Radiation of an Elastomer Modified Bitumen, Fuel, Vol. 87, 2008, pp. 2408-2419.

[101] Newcomb, D. E. (2006). "An Introduction to Warm Mix Asphalt." National Asphalt Pavement Association, Webaccess from http://fs1.hotmix.org/mbc/Introduction to Warmmix_Asphalt.pdf.

[102] Newcomb, D. E. (2008). "Warm Mix Asphalt Heats Up." Paving the Way, Pennsylvania Asphalt Pavement Association, 9 (1), January/February/March. 162.

[103] Nourendin, A. S. and Wood, L. E. (1989). "Variation in Molecular Size Distribution Virgin and Recycled Binders Associated with Aging." Transportation Research Record, No. 1228, TRB, National Research Council, Washington, D. C., 191-197.

[104] NPI. (1999). "Emission Estimation Technique Manual for Hot Mix Asphalt Manufacturing” National Pollutant Inventory.

[105] Ott, R. L., and Longnecker, M. (2001). "An Introduction to Statistical Methods and Data Analysis." Duxbury Press, 5th edition, ISBN-10: 0534251226.

[106] Provell, B. D. (2007). "Warm Mix Asphalt." The international technology scanning program, 13-14.

[107] Oliver and Tredrea (1997) THE CHANGE IN PROPERTIES OF POLYMER MODIFIED BINDERS WITH SIMULATED FIELD EXPOSURE (WITH DISCUSSION) JWH Oliver, PF Tredrea - Journal of the Association of Asphalt Paving ..., 1997 - trid.trb.org.

[108] Prowell, B. D., Hurley, G. C., and Crews, E. (2007). "Field Performance of Warm- Mix Asphalt at National Center for Asphalt Technology Test Track."Journal of the Transportation Research Board, No. 1998.

[109] Prowell, B., (2007). "Scan Tour Examines Warm-Mix in Europe" Hot Mix Asphalt Technology, National Asphalt Pavement Association, Lanham, MD, September/October, 1523, (b).

[110] Prowell. B. (2007). "Warm Mix Asphalt" The International Technology Scanning Program Summary Report, (a).

[111] Punith, V. S. (2005). "Studies on the Performance of Bituminous Paving Mixtures utilising Recycling Plastics." Dissertation, Department of Civil Engineering, Bangalore University, Bangalore, India.

[112] Putman, B. J., and Amirkhanian, S. N. (2006). "Laboratory Evaluation of Anti-Strip Additives in Hot Mix Asphalt." Clemson University, Report No. FHWA-SC-06-07.

[113] Rajpal, S. (2005). "Rutting Potential of Polymer Modified Hot Mix Asphalt Concrete Mixtures." Thesis, Department of Civil Engineering, University of Texas at El Paso, 7-8. 
[114] Roberts, F. L., Kandhal, P. S., Brown, E. R., Lee, D. Y., and Kennedy, T. W. (1996). "Hot Mix Asphalt Materials, Mixture Design, and Construction." NAPA Researchand Education Foundation, Lanham, MD.

[115] Romier, A., Audeon, M., David, J., Martineau, Y., and Olard, F. (2006). "Low- Energy Asphalt with Performance of Hot-Mix Asphalt." Journal of the Transportation Research Board, No. 1962. 163.

[116] Roque, R., Birgisson, B., Drakos, Christos., and Sholar, G. (2005). "Guidelines for Use of Modified Binders." University of Florida, Report No. 4910-45054-964-12, 7- 13.

[117] Rozeveld, S. J., Shin, E. E., Bhurke, A., France, Larry., and Drzal, L. T. (1997). "Network Morphology of Straight and Polymer Modified Asphalt Cements." Microscopy Research and Technique, 38 (5), 529-543.

[118] Russel, P., and Batchelor, D. (2004). "SEM and AFM: Complementary Techniques for High Resolution Surface Investigations."Vecco Instruments Inc.

[119] Rek, V., Vranješ, N. and Barjaktarović, Z. M., Evaluation of Ageing Properties of Polymer Modified Bitumen, Materials Research Innovations, Vol. 9, No. 4, 2005, pp. 670-691.

[120] Sasol Wax Website: http://www.sasolwax.com/.

[121] Sengoz, B., and Isikyakar, B. (2008). "Analysis of StyreneButadiene-Styrene Polymer Modified Bitumen using Fluorescent Microscopy and Conventional Test Methods." Journal of Hazardous materials, 150 (2), 424-425.

[122] Safaei, F., Lee, J., Nascimento, L. A. H. D., Hintz, C. andKim, Y. R. Implications of Warm-mix Asphalt on Long-term Oxidative Ageing and Fatigue Performance of Asphalt Binders and Mixtures, Road Materials and Pavement Design, Vol. 15, 2014, pp. 45-61.

[123] Shull, J. (1995). "An Investigation of the Fundamental Chemical, Physical, and Thermodynamic Properties of Polymer Modified Asphalt Cements." Thesis, Department of Chemical Engineering, Michigan State University, E. Lansing, MI.

[124] Suttmeier, C. (2006). "Warm Mix Asphalt: A Cooler Alternative" Material Matter.

[125] Siddiqui, M. N. and Ali, M. F., "Studies on the Aging Behavior of the Arabian Asphalts", Fuel, Vol. 78, 1999, pp. 1005-1015.

[126] Singh, M. and Kumar, P., Laboratory Study on Bitumen Modification for Improved Physical, Rheological Properties and the Effect Of Short Term Ageing, in the proceedings of 25th ARRB Conference-Shaping the future: Linking policy, research and outcomes.

[127] Spring, 21-22. USEPA.(2000). "Hot Mix Asphalt Plants Emission Assessment Report” EPA-454/R- 00-019.

[128] Sustersic, E, Tusar M and valant A. Z Rheological and mechanical characterization of waste PMMA/ATH Modified Bitumen, Construction and Building Materials, Vol. 38, 2013, PP. 119-125.

[129] Stuart, K. D. (2001). Methodology for Determining Compaction Temperatures for Modified Asphalt Binders, Federal Highway Administration, McLean.

[130] Stuart, (2001) Analysis of rutting prediction criteria using a nonlinear viscoelastic model SP Atul Narayan, DN Little... Journal of Materials in ..., 2014 - ascelibrary.org ... (1997) and Stuart et al. (1999) ... Shenoy's oscillatory based parameter is another ruttingparameter that has been found to work reasonably well by Shenoy $(2001,2004 a)$. In field investigations conducted by Rowe et al ... SBS 64-40, 3.0\% SBS, $71-38 \ldots$

[131] Virginia DOT. "Chapter 7: Testing of Asphalt Concrete Mixtures." Web access fromhttp://www.virginiadot.org/business/resources/Materials/ MCS_Study_Guides/bu-mat- Chapt7AP.pdf.

[132] Veeraragavan et al (2008) Evaluation of the master curves or complex shear modulus for nano-modified asphalt binders $\mathrm{H}$ Yao, Z You, L Li, SW Goh...- CICTP 2012: Multimodal ..., 2012 - ascelibrary.org ... 2007; Goh and You 2009; Liu et al. 2011)... "The Effect of SBS on Asphalt and SMA Mixture Properties." Journal of Materials in Civil Engineering, 23 (4), 504-510. Al-Hadidy, AI, and Yi-qiu, T. (2010)... Awanti, SS, Amarnath, MS, and Veeraragavan, A. (2008).

[133] Wasiuddin, N. M., Zaman, M. M., and O’Rear, E. A. (2008). "Effect of Sasobit and Aspha-min on Wettability and Adhesion between Asphalt Binders and Aggregates." Transportation Research Record, Vol. 2051, 80-89.

[134] Wu. S., Pang, L. Liu, G. and Zhu, J., Laboratory Study on Ultraviolet Radiation Aging of Bitumen, Journal of Materials in Civil Engineering, Vol. 22, No. 8, 2010, pp. 767-772.

[135] Wasiuddin, N. M., Selvamohan, S., Zaman, M. M., and Guegan, M. L. T. A. (2007). "Comparative Laboratory Study of Sasobit and Aspha-min Additives in Warm-Mix Asphalt." Transportation Research Record, Vol. 1998, 82-88.

[136] Wu, S., Pang, L., Moa, L., Chen, Y. and Zhu, G., Influence of Aging on the Evolution of Structure, Morphology and Rheology of Base and SBS Modified Bitumen Construction andBuilding Materials, Vol. 23, 2009, pp. 105-1010.

[137] Xiao, F., and Amirkhanian, S. N. 2009_."Laboratory investigation of moisture damage in rubberized asphalt mixtures containing reclaimedasphalt pavement." Int. J. Pavement Eng., 10_5_, 319-32.

[138] Xiaohu, L. and Isacsson, U., Effect of Ageingon Bitumen Chemistry and Rheology, Construction and Building Materials, Vol. 16, 2002, pp. 15-22.

[139]X., and lsacsson, U., Effect of ageing on bitumen chemistry and rheology, Construction and Building Materials, Vol. 16, 2002, pp. 15-22.

[140] Yildirim, Y., Solaimanian, M., and Kennedy, T. W. (2000). Mixing and Compaction Temperatures for Hot Mix Asphalt Concrete, pp. 100, University of Texas, Austin Asphalt Concrete, pp. 100, University of Texas, Austin.

[141] Zubeck, H. K., Raad, L., Saboundjian, S., Minassian, G., and Ryer., J. (2003). "Workability and Performance of Polymermodified Asphalt Aggregate Mixtures in Cold Regions." International Journal of Pavement Engineering, Vol. 49 (1), 25-36.

[142] Zhange et al (2011) Xiao, F., Wenbin Zhao, P. E., \&Amirkhanian, S. N. (2009). Fatigue behavior of rubberized asphalt concrete mixtures containing warmasphalt additives. Construction and Building Materials, 23 (10), pp. 3144-3151. Construction and Building Materials, 21 (1), pp. 6672. 
[143] Zaumanis, M., \& Haritonovs, V. (2010). Research on properties of Warm Mix Asphalt. scientific proceedings of Riga Technical University, Series 2: Architecture and Construction Science.
[144] Zhang, J., Wang, J., Wu, Y., Sun, W., \& Wang, Y. (2009). Thermal behavior and improved properties of SBR and SBR/natural bitumen modified bitumen. Iranian Polymer Journal, 18 (6), pp. 465-478. 